\title{
Modeling and Computational Strategies for Optimal Development Planning of Offshore Oilfields under Complex Fiscal Rules
}

\author{
Vijay Gupta ${ }^{1}$ and Ignacio E. Grossmann ${ }^{2}$ \\ Department of Chemical Engineering, Carnegie Mellon University \\ Pittsburgh, PA 15213
}

\begin{abstract}
The main goal of this paper is to extend a simple NPV (net present value) based optimal oilfield development planning model to include complex fiscal rules. In particular, we consider a recently proposed multi-field site strategic planning model for offshore oil and gas fields as a basis to include the generic fiscal rules with ringfencing provisions. The reduction of this model to a variety of contracts is explained. The results on the realistic instances show improved investment and operations decisions due to the explicit consideration of the fiscal terms during planning. However, as the model can become computationally very expensive to solve with the extension to sliding scale fiscal rules, we also provide some reformulation/approximation techniques and solution strategies that yield orders of magnitude reduction in the solution time.
\end{abstract}

Keywords: Multiperiod Optimization, Oil and Gas field planning, Production sharing agreements, Royalties, Fiscal Rules, Mixed-integer programming.

\section{Introduction}

Offshore oil and gas field development planning has received significant attention in recent years given the new discoveries in the last decade of large oil and gas reserves around the world. These have been facilitated by the new technologies available for exploration and production of oilfields in remote locations that are often hundreds of miles offshore and significant increase in the oil/gas prices to make the production economically viable. Surprisingly, there has been a net increase in the total oil reserves in the last decade because of these discoveries despite increase in the total demand (BP, Statistical review Report ${ }^{1}$ ). Therefore, there is currently a strong focus on exploration and development activities for new oil fields, specifically at offshore locations.

\footnotetext{
${ }^{1}$ E-mail: vijaygup@andrew.cmu.edu

${ }^{2}$ Corresponding author. E-mail: grossmann@cmu.edu
} 
These development projects involve capital intensive decisions pertaining to the installation of exploration and production facilities, subsea structures, pipeline connections, well drilling, etc. that are made at the early stages of the project. However, there is a very large number of alternatives that are usually available to make these decisions under the given physical and practical restrictions. This motivates the need for optimizing the investment and operations decisions to ensure the highest return on the investments over the given time horizon. There are several deterministic models that have been proposed for the oil/gas field infrastructure planning problem (Lee and Aranofsky², Aronofsky and Williams ${ }^{3}$, Frair ${ }^{4}$, Bohannon ${ }^{5}$, Sullivan ${ }^{6}$, Haugland et al. ${ }^{7}$, Behrenbruch ${ }^{8}$, Iyer et al. ${ }^{9}$, Van den Heever and Grossmann ${ }^{10}$, Kosmidis et al. ${ }^{11}$, Barnes et al. $^{12}$, Ortiz-Gomez et al. ${ }^{13}$, Tsarbopoulou ${ }^{14}$, Carvalho and Pinto ${ }^{15,16}$, Gupta and Grossmann ${ }^{17}$ ). The uncertainties in the model parameters have also been addressed using stochastic programming approaches $\left(\right.$ Haugen $^{18}$, Jonsbraten ${ }^{19,20}$, Aseeri et al. ${ }^{21}$, Lund ${ }^{22}$, Cullick et al. ${ }^{23}$, Goel and Grossmann ${ }^{24,25,26}$, Tarhan et al. ${ }^{27,28}$, Gupta and Grossmann ${ }^{29}$ ). The major limitation with these models is that they do not consider the fiscal rules explicitly in the optimization model that are associated to these fields, and rely on the simple NPV for deterministic or expected NPV for stochastic programming as an objective function. Therefore, the models with these objectives may yield the solutions that are very optimistic, which can in fact be suboptimal after

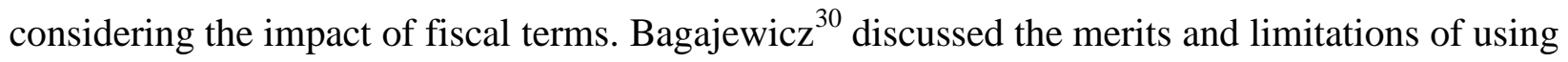
NPV in the investment planning problems and pointed out that additional consideration and procedures are needed for these problems, e.g. return on investments, to make the better decisions. Laínez et al. ${ }^{31}$ emphasizes that enterprise-wide decision problems must be formulated with realistic detail, not just in the technical aspects, but also in the financial components in order to generate solutions that are of value to an enterprise. This requires systematically incorporating supplier/buyer options contracts within the framework of supply-chain problems.

In the context of oilfield planning, fiscal rules of the agreements between the oil company (contractor) and the host government, e.g. production sharing contracts, usually determine the share of each of these entities in the total oil production or gross revenues and the timing of these payments. Hence, including fiscal considerations as part of the oilfield development problem can significantly impact the optimal decisions and revenue flows over the planning horizon, as a large fraction of the total oil produced is paid as royalties, profit share, etc. The models and solutions approaches in the literature that consider the fiscal rules within oilfield infrastructure 
planning are either very specific or simplified. Van den Heever et al. ${ }^{32}$ and Van den Heever and Grossmann $^{33}$ considered optimizing the complex economic objectives including royalties, tariffs, and taxes for the multiple gas field site where the schedule for the drilling of wells was predetermined as a function of the timing of the installation of the well platform. Moreover, the fiscal rules presented were specific to the gas field site considered, but not in generic form. Based on a continuous time formulation for gas field development with complex economics of similar nature as Van den Heever and Grossmann ${ }^{33}$, Lin and Floudas ${ }^{34}$ proposed an MINLP model and solved it with a two-stage algorithm. Approaches based on simulation (Blake and Roberts $^{35}$ ) and meta-modeling (Kaiser and Pulsipher ${ }^{36}$ ) have also been considered for the analysis of the different fiscal terms. Gupta and Grossmann ${ }^{37}$ recently proposed a unified modeling framework with a detailed literature review to address the issue of uncertainties and fiscal rules for the problems in this class.

In this paper, we address the optimal development planning of offshore oil and gas fields under complex fiscal rules considering as a basis the deterministic model for multi-field site by Gupta and Grossmann ${ }^{17}$, which includes sufficient level of detail to be realistic as well as being computationally efficient. The proposed model considers the trade-offs between optimal investment and operations decisions that correspond to the simple NPV based model and resulting overall NPV for the oil company after paying government share, and yields improved decisions in a more realistic setting for the enterprise (see Figure 1).

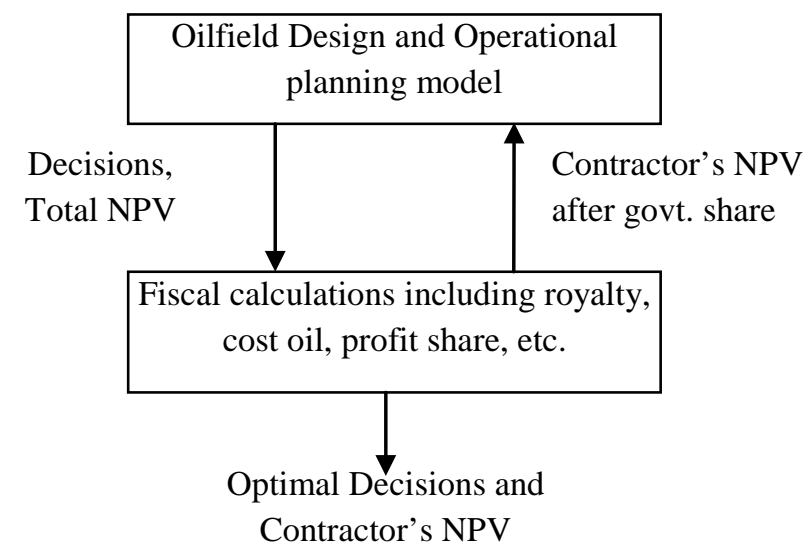

Figure 1. Oilfield Planning with fiscal considerations

We first discuss the basic elements of the various types of contracts, fiscal terms, and present a generic oilfield planning model with fiscal considerations that includes ringfencing provisions. The ringfencing provisions in a contract divide the fields in certain groups such that 
only fields in a given ringfence can share the cost and revenues for fiscal calculations, but not with the fields from other ringfences. Therefore, these provisions further increase the complexity of the model (see section 2(c) for more details). The ways to derive a specific contract from the generic model are highlighted next. Numerical results of several instances of the development planning problem under complex fiscal rules are reported. New reformulation/approximation schemes and solution strategies are also proposed to reduce the computational burden for the problems in this class.

\section{Background}

\section{(a) Type of Contracts}

When an oil company needs to sign a contract or agreement with the host government to explore and develop the petroleum resources in a country, there are a variety of contracts that are used in the offshore oil and gas industry (Babusiaux et al. ${ }^{38}$, Johnston $^{39}$, Sunley et al. ${ }^{40}$, Tordo ${ }^{41}$ ). Although the terms of a particular agreement are usually negotiated between both the entities in practice, these contracts can broadly be classified into two main categories:

\section{(i) Concessionary System}

A concessionary (or tax and royalty) system usually involves royalty, cost deduction and tax. Royalty is paid to the government at a certain percentage of the gross revenues. The net revenue after deducting costs becomes taxable income on which a pre-defined percentage is paid as tax which may include both corporate income tax and a specific profit tax. The total contractor's share involves gross revenues minus royalty and taxes in each year. The basic difference as compared to the production sharing agreement is that the oil company keeps the right to all of the oil and gas produced at the wellhead and pays royalties, bonuses, and other taxes to the government. These contracts are used in countries such as Canada, USA and the UK.

\section{(ii) Production Sharing Agreements (PSAs)}

The revenue flow in a typical Production Sharing Agreement can be seen as in Figure 2 (World Bank $^{42}$ ). First, in most cases, the company pays royalty to the government at a certain percentage of the total oil produced. After paying the royalties, some portion of the remaining oil is treated as cost oil by the oil company to recover its costs. There is a ceiling on the cost oil recovery to ensure revenues to the government as soon as production starts. The remaining part of the oil, called profit oil, is divided between oil company and the host government at a certain percentage. 
The oil company needs to further pay income tax on its share of profit oil. Hence, the total contractor's (oil company) share in the gross revenue comprises of cost oil and contractor's profit oil share after tax. The other important feature of a PSA is that the government keeps rights to the oil produced at wellhead, and transfers title to a portion of the extracted oil and gas to oil company that works as a contractor at an agreed delivery point. Notice that the cost oil limit is one of the key differences with a concessionary system. These contracts are used in countries such as Cambodia, China, Egypt, India, Angola and Nigeria.

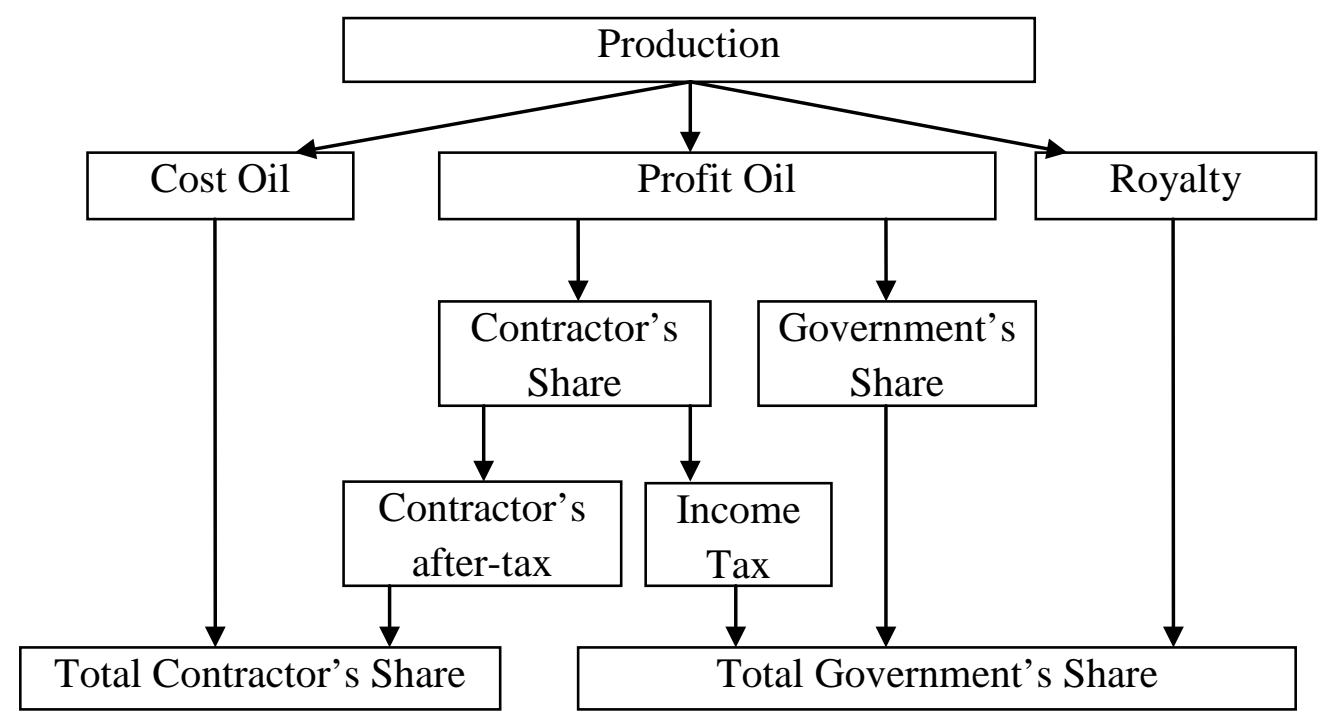

Figure 2: Revenue flow for a typical Production Sharing Agreement

\section{(b) Type of Fiscal terms for Concessionary Systems and PSA}

The specific rules defined in such a contract (either concessionary or PSA, hybrid) between oil company and host government determine the profit that the oil company can keep, as well as the royalties and profit oil share that are paid to the government. These profit oil fractions, royalty rates define the fiscal terms of a particular contract and can be either of the following two types:

\section{(i) Regressive Fiscal Terms:}

These fiscal terms are not directly linked to the profitability of the project, e.g. fixed percentage of royalty or profit oil share for the entire planning horizon. Therefore, the so called tier structure (levels) is usually absent.

\section{(ii) Progressive (Sliding scale) Fiscal Terms:}

In this case fiscal terms (e.g. profit oil shares, royalty rates) are based on the profitability of the project, i.e. these terms penalize higher production rates, where cumulative oil produced, daily 
production, rate of return, R-factor, are the typical profitability measures that determine the tier structure (levels) for these contract terms. For instance, if the cumulative production is in the range of first tier, $0 \leq x c_{t} \leq 200$, the contractor receives $50 \%$ of the profit oil, while if the cumulative production reaches in tier $2,200 \leq x c_{t} \leq 400$, the contractor receives $40 \%$ of the profit oil, and so on (see Figure 3). In practice, as we move to the higher tier, the percentage share of contractor in the total production decreases. Notice that this tier structure is a step function, which requires additional binary variables to model and makes the problem harder to solve.

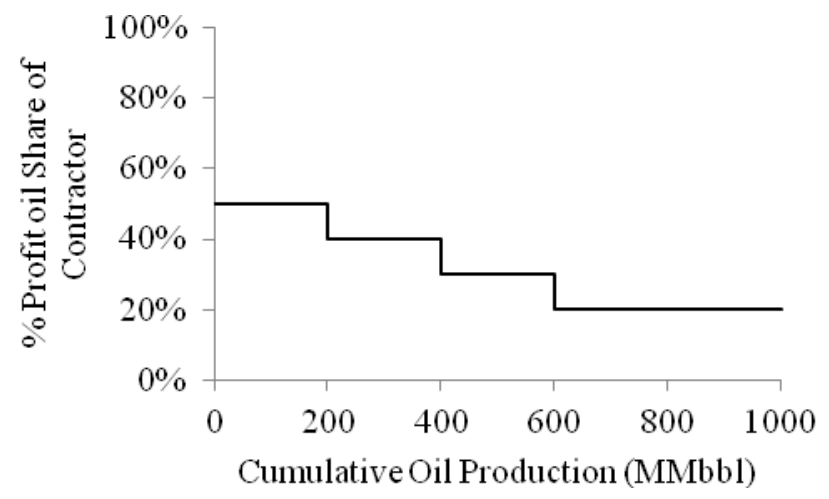

Figure 3: Progressive profit oil share of the contractor

\section{(c) Ringfencing Provisions:}

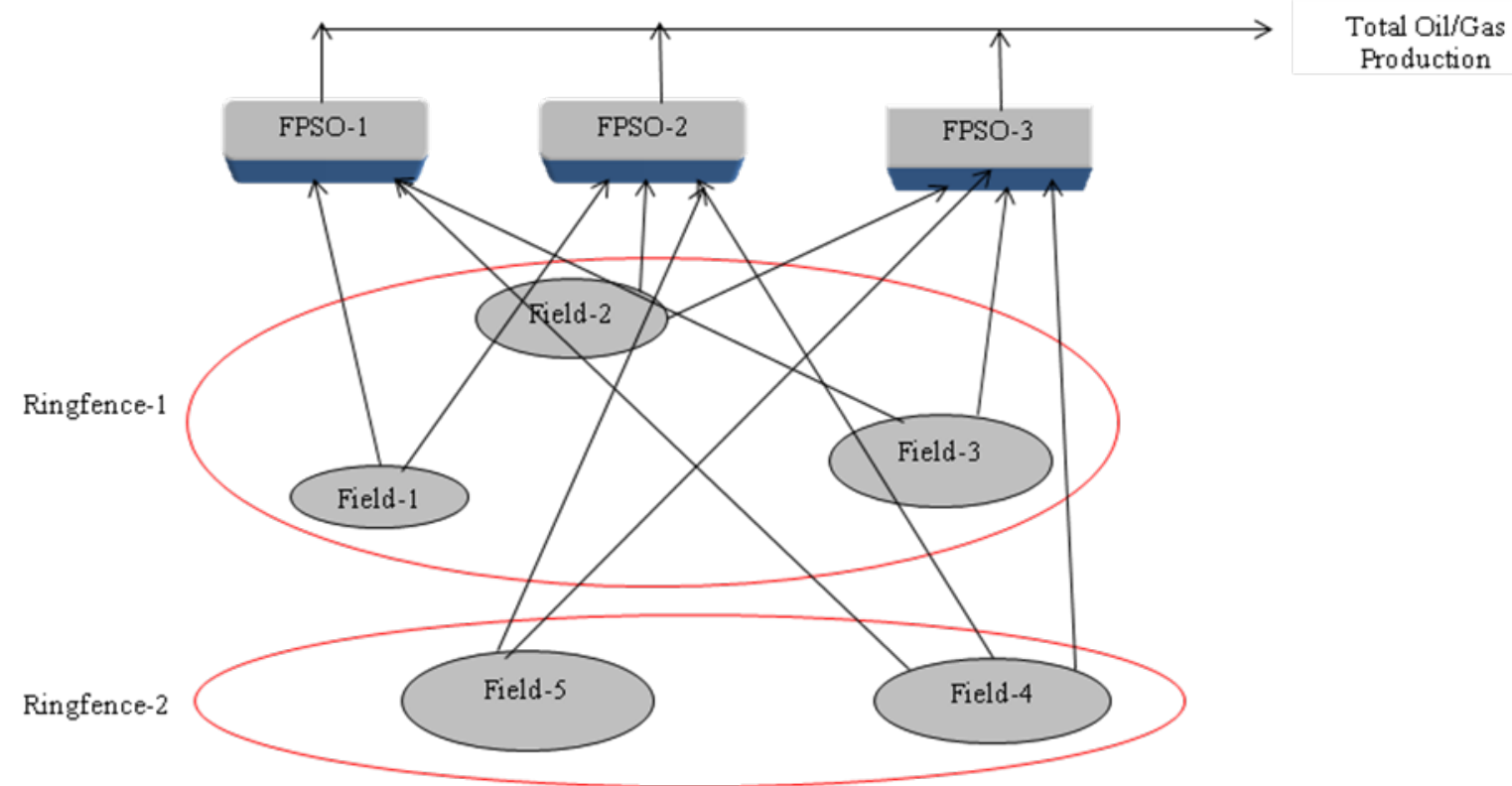

Figure 4: 2 Ringfences for a set of 5 Fields

Ringfencing is an important concept that is usually part of the fiscal contracts and imposed by the government, which affects the cash flows over the planning horizon. In a typical 
ringfencing provision, investment and operational costs for a specified group of fields or block can only be recovered from the revenue generated from those fields or block (see Figure 4). It means that the set of particular fields are "ring-fenced". Therefore, income derived from one contract area or project cannot be offset against losses from another contract area or project. In financial terms, a ringfencing provision basically defines the level at which all fiscal calculations need to be done, and restricts the oil companies to balance the costs and revenues across various projects/blocks for minimizing the tax burden. For example, fiscal calculations for Fields 1-3 (Ringfence 1) and Field 4-5 (Ringfence 2) in Figure 4 cannot be consolidated at one place. Notice that in general a field is associated to a single ringfence, while a ringfence can include more than one field. In contrast, a facility can be connected to multiple fields from different ringfences for producing oil and gas. Ringfencing provisions are more popular in production sharing contracts.

The main motivation of including ringfencing provisions by the host governments is to protect the tax revenues. However, the existence and extent of ringfencing affects the overall level of tax receipts. The more restrictive ringfencing provisions (e.g. individual field is separately ringfenced) can lead to situations that may not be economically viable to develop/operate for the oil companies. On the other hand, the relaxation of the ringfencing provisions (e.g. cost and revenues can be shared across any field for tax calculations) may lead to significant tax saving for the oil companies since revenues from the favorable fields can be used to offset the losses from other fields. Therefore, the number of ringfences and distribution of the fields among ringfences involve various trade-offs that include productivity of the field, crude quality, reservoir size, development costs etc., so that these fiscal provisions are neither very conservative nor very relaxed. Moreover, each ringfence can be assigned a different cost recovery limit, profit sharing rate etc. based on these factors.

Ringfencing provisions and income tax rates are usually legislated in the country and do not provide opportunity for negotiation, while cost recovery and profit sharing rates can be subject to negotiation. Therefore, from the prospective of the oil companies, since they have limited control over the ringfencing provisions and distribution of fields among various ringfences, they usually try to include many fields from multiple ringfences in the model for making investment and operational decisions that allows to consider the trade-offs among these fields and/or ringfences. In general, it is better to have more fiscal aspects of a contract that are 
subject to negotiation, since flexibility is often required to offset differences between basins, regions, and license areas within a country ${ }^{39}$.

The above fiscal contracts, terms and ringfencing provisions are the backbone of most of the contracts that are currently used, and can have significant impact on the revenues. In addition, there can be some other fiscal considerations for a particular contract of interest, but for simplicity we only consider the important financial elements as described above. Notice that the royalties and/or government profit oil share that result from a particular contract can represent a significant amount of the gross revenues. Therefore, it is critical to consider these contract terms explicitly during the oilfield planning phase to assess the actual economic potential of such a project. In the next section, we discuss how to include progressive PSA with ringfencing provisions in oilfield infrastructure planning model that encapsulates the key elements of the most of the available contracts, and represent one of the most general forms of fiscal terms.

\section{Problem Statement}

A typical offshore oilfield infrastructure consists of a set of oil fields $F=\{1,2, \ldots\}$ for producing oil using a set of FPSO (Floating, Production, Storage and Offloading) facilities, FPSO = $\{1,2, \ldots\}$ as seen in Fig. 4 that can process the produced oil, store and offload it to the other tankers. Each oilfield consists of a number of potential wells to be drilled using drilling rigs, which are then connected to these FPSO facilities through pipelines to produce oil. We assume that the location of each potential FPSO facility and its possible connections to the given fields are known. Notice that each FPSO facility can be connected to more than one field to produce oil, while a field can only be connected to a single FPSO facility due to practical engineering requirements and economic viability of the offshore oilfield development projects. There can be a significant amount of water and gas that comes out with the oil during the production process that needs to be considered while planning for FPSO capacity installations and expansions. The water is usually re-injected after separation from the oil, while the gas can be sold in the market. In this case we do not consider water or gas re-injection, i.e. we consider natural depletion of the reserves. For simplicity, we only consider FPSO facilities. The proposed model can easily be extended to other facilities such as tension leg platforms (TLPs).

In addition, there are fiscal aspects that need to be accounted for. Particularly, we

consider the cost recovery ceiling that is linked to gross revenues, profit oil share and taxes as the 
main elements of the fiscal terms (see Figure 2). Progressive (sliding scale) profit share of the contractor is also considered that can be linked to any of the profitability measures, e.g. cumulative oil produced, daily oil production, R-factor, IRR, where $I=\{1,2, \ldots\}$ is the set of corresponding tiers for this sliding scale. The definition of R-factor can be contract specific, but in its most general form, it is calculated as the ratio of the contractor's cumulative revenue after taxes and royalty to the contractor's cumulative $\operatorname{cost}^{36}$. On the other hand, the internal rate of return (IRR) on an investment or project is defined as the "annualized effective compounded return rate" or "rate of return" that makes the net present value of the cash flows (both positive and negative) from a particular investment equal to zero. In general, as values of the above profitability measures increase, the profit oil share of the contractor decreases.

Notice that we do not consider explicit royalty provisions here as cost oil ceiling and royalties both are usually not imposed simultaneously in a PSA contract. However, including royalty provisions with cost oil ceiling is straightforward. A set of ringfences $R F=\{1,2, \ldots\}$ among the given fields is specified (see Figure 4) to ensure that fiscal calculations are to be done for each ringfence separately. These ringfences may or may not have the same fiscal rules. Notice that, the fiscal terms considered here collectively define a generic progressive PSA with ringfencing provisions. The variety of other contracts can be derived as a special case from these rules. Notice that for simplicity, the cost recovery ceiling fraction and tax rates are assumed to be fixed percentages (no sliding scale). However, for the problems where these fiscal terms are also progressive, a similar approach as used for progressive profit oil fraction can directly be applied.

The objective is to determine the optimum investment and operation decisions to maximize the contractor's NPV for a long-term planning horizon after paying the government share based on the above fiscal considerations. The planning horizon is discretized into a number of time periods $t$, typically each with 1 year of duration. Investment decisions in each time period $t$ include, which FPSO facilities should be installed or expanded, and their respective installation or expansion capacities for oil, liquid and gas, which fields should be connected to which FPSO facility, and the number of wells that should be drilled in a particular field $f$ given the restrictions on the total number of wells that can be drilled in each time period $t$ over all the given fields. Operating decisions include the oil/gas production rates from each field $f$ in each time period $t$. It is assumed that the installation and expansion decisions occur at the beginning of each time period $t$, while operation takes place throughout the time period. There is a lead time of $l_{1}$ years 
for each FPSO facility initial installation, and a lead time of $l_{2}$ years for the expansion of an earlier installed FPSO facility. Once installed, we assume that the oil, liquid (oil and water) and gas capacities of a FPSO facility can be expanded only once.

Field deliverability, i.e. maximum oil flowrate from a field, water-oil-ratio (WOR) and gas-oil-ratio (GOR) are approximated by a cubic equation (a)-(c), while cumulative water produced and cumulative gas produced from a field are represented by fourth order separable polynomials, eq. (d)-(e), in terms of the fractional oil recovered from that field, respectively. Notice that these fourth order polynomials correspond to the integration of the cubic equations for WOR and GOR as explained in Gupta and Grossmann ${ }^{17}$. The motivation for using polynomials for cumulative water produced and cumulative gas produced, eq. (d)-(e), as compared to WOR and GOR, eq. (b)-(c), is to avoid bilinear terms, eq. (f)-(g), in the formulation and allow converting the resulting model into an MILP formulation. Furthermore, all the wells in a particular field $f$ are assumed to be identical for the sake of simplicity leading to the same reservoir profiles, eq. (a)-(g), for each of these wells.

$$
\begin{array}{lc}
Q_{f}^{d}=a_{1, f}\left(f c_{f}\right)^{3}+b_{1, f}\left(f c_{f}\right)^{2}+c_{1, f} f c_{f}+d_{1} & \forall f \\
\text { wor }_{f}=a_{2, f}\left(f c_{f}\right)^{3}+b_{2, f}\left(f c_{f}\right)^{2}+c_{2, f} f c_{f}+d_{2, f} & \forall f \\
g o r_{f}=a_{3, f}\left(f c_{f}\right)^{3}+b_{3, f}\left(f c_{f}\right)^{2}+c_{3, f} f c_{f}+d_{3, f} & \forall f \\
w c_{f}=a_{4, f}\left(f c_{f}\right)^{4}+b_{4, f}\left(f c_{f}\right)^{3}+c_{4, f} f c_{f}^{2}+d_{4, f} f c_{f} & \forall f \\
g c_{f}=a_{5, f}\left(f c_{f}\right)^{4}+b_{5, f}\left(f c_{f}\right)^{3}+c_{5, f} f c_{f}^{2}+d_{5, f} f c_{f} & \forall f \\
w_{f}=\text { wor }_{f} \cdot x_{f} & \forall f \\
g_{f}=g o r_{f} \cdot x_{f} & \forall f
\end{array}
$$

A generic MINLP model for oilfield development planning with fiscal considerations is presented next based on the infrastructure, fiscal terms and reservoir characteristics described in this section.

\section{Oilfield Development Planning Model}

\section{(a) Models without fiscal considerations:}


Gupta and Grossmann ${ }^{17}$ recently proposed efficient multiperiod MINLP models (Models 1 and 2) for oilfield infrastructure planning problem described above without fiscal considerations. Model 2 is also reformulated into an MILP (Model 3) to solve it to global optimality. These models were further reduced (Models 1R, 2R and 3R) by neglecting the timing of the piping investments to improve the computational efficiency. The basic features of these models can be summarized as follows:

Model 1: MINLP based on WOR, GOR and corresponding bilinear terms

Model 2: MINLP based on separable functions for cumulative water and cumulative gas produced derived from integration of WOR and GOR expressions

Model 3: Derived from MINLP Model 2 using piecewise linearization and exact linearization techniques

Model 1R, 2R and 3R: Derived from corresponding Models 1, 2, and 3, respectively, using binary reduction scheme that relies on the fact that connection costs are much smaller as compared to other investment costs.

Based on the computational experience by Gupta and Grossmann ${ }^{17}$, Model 3R is the most efficient as it can directly be solved to global optimality in reasonable time as compared to other models. Furthermore, its solution can be used to fix the design decisions in the MINLP models to obtain near optimal solutions of these models.

\section{(b) Proposed Models with fiscal considerations:}

In this section, we incorporate the complex fiscal rules in the above MINLP/MILP models. Particularly, we consider the progressive PSA with ringfencing provisions that is the most general form of fiscal terms. The proposed models consider the trade-offs involved between investment and operations decisions and resulting royalties, profit shares that are paid to the government, and yields the maximum overall NPV for the contractor (see Fig. 1) due to improved decisions.

(i) Objective Function: The objective function is to maximize total NPV of the contractor as in (1), which is the difference between discounted total contractor's gross revenue share and total cost (total capital plus operating costs) over the planning horizon (2). The total contractor's share in a particular time period $t$ is the sum of the contractor's share over all the ring-fences as given in equation (3). Similarly, constraints (4) and (5) represent the total capital and 
operating expenses in time period t, which is the sum of respective costs over all the ringfences in that time period.

Max NPV

$N P V=\sum_{t} d i s_{t} \cdot\left(\right.$ TotalConSh $\left._{t}^{\text {tot }}-C A P_{t}^{\text {tot }}-O P E R_{t}^{\text {tot }}\right)$

TotalConSh $_{t}^{\text {tot }}=\sum_{r f}$ TotalConSh $_{r f, t}$

$\forall t$

$C A P_{t}^{\text {tot }}=\sum_{r f} C A P_{r f, t} \quad \forall t$

$O P E R_{t}^{\text {tot }}=\sum_{r f} O P E R_{r f, t} \quad \forall t$

(ii) Capital Costs: The overall capital expenses associated to a ring-fence $r f$ contains two components as given in equation (6), see Figure 4. One capital cost component, equation (7), is field specific and accounts for the connection costs between a field and a FPSO facility, and cost of drilling the wells for each of the field in that ring-fence $r f$, i.e. set $F_{r f}$, for each time period t. The second capital cost component for a ring-fence is FPSO specific as given in equation (8), and it depends on the capital expenses for the corresponding FPSO facilities that are installed during the planning horizon.

$$
\begin{array}{ll}
C A P_{r f, t}=C A P 1_{r f, t}+C A P 2_{r f, t} & \forall r f, t \\
C A P 1_{r f, t}=\sum_{F_{r f}} \sum_{f p s o} F C_{f, f p s o t} b_{f, f p s o, t}+\sum_{F_{r f}} F C_{f, t}^{\text {well }} I_{f, t}^{\text {well }} & \forall r f, t \\
C A P 2_{r f, t}=\sum_{f p s o} D F P S O C_{r f, f p s o, t} & \forall r f, t
\end{array}
$$

The total cost of an FPSO facility (9) consists of fixed installation costs, variable installation and expansion costs corresponding to liquid and gas capacities. Each FPSO facility can be connected to multiple fields from different ringfences as can seen from Figure 4. Therefore, to calculate the second cost component in (8) for a specific ring-fence these FPSO costs need to be disaggregated as in (10) over various fields (and therefore ring-fences as in (11)) based on the size of the fields, where set $F_{f p s o}$ is the set of all the fields that can be connected to FPSO facility fpso. Constraint (12) sets the binary variable $b_{f, \text { fpso }}^{\text {on }}$ to 1 only if that field-FPSO 
connection comes online during the given planning horizon. This binary variable is further used in constraint (13) to ensure that the disaggregated FPSO cost can only be accounted for a field if that field is connected to the FPSO facility. Constraint (14) calculates the value of disaggregated FPSO cost for a specific field based on the ratio of the size of that field to sum of the total field sizes that are connected to that FPSO facility during given planning horizon. Notice that only those fields sizes are considered for calculations that are actually connected to that FPSO facility, i.e. for which the binary variable $b_{f, f p s o}^{o n}$ equals 1 . In general, we consider a long planning horizon for the development planning in which the fields may not be depleted completely during this time horizon. However, the installed FPSO facilities and connections usually remain in operation until it becomes uneconomical to produce from the given fields, which may exceed few years over the time horizon considered in the planning model. Therefore, it allows us to disaggregate the FPSO costs over the various ringfences based on the recoverable volume of the oil from a field as described above to be sufficiently accurate and computationally efficient by avoiding nonlinearities.

$$
\begin{aligned}
& \text { FPSOC }_{f p s o, t}=\left[F C_{f p s o, t}^{F P S O} b_{f p s o, t}^{F P S O}+V C_{f p s o, t}^{\text {liq }}\left(Q I_{f p s o, t}^{l i q}+Q E_{f p s o, t}^{l i q}\right)+V C_{f p s o, t}^{\text {gas }}\left(Q I_{f p s o, t}^{g a s}+Q E_{f p s o, t}^{g a s}\right)\right] \\
& \forall \text { fpso, } t \\
& \text { FPSOC }_{f p s o, t}=\sum_{F_{f p s o}} \text { DFPSOC }_{f, f p s o, t}^{\text {field }} \quad \forall \text { fpso,t } \\
& \operatorname{DFPSOC}_{r f, f p s o, t}=\sum_{F_{r f}} \text { DFPSOC }_{f, f p s o, t}^{\text {field }} \quad \forall r f, \text { fpso, } t \\
& b_{f, f p s o}^{o n}=\sum_{t} b_{f, f p s o, t} \quad \forall f, \text { fpso } \\
& \operatorname{DFPSOC}_{f, f p s o, t}^{\text {field }} \leq M \cdot b_{f, f p s o}^{o n} \quad \forall f, \text { fpso, } t \\
& \operatorname{DFPSOC}_{f, f p s o, t}^{\text {field }}=\frac{b_{f, f p s o}^{\text {on }} \cdot R E C_{f}}{\sum_{f^{\prime} \in F_{\text {fpso }}} b_{f^{\prime}, f p s o}^{\text {o }} \cdot R E C_{f^{\prime}}} \cdot \text { FPSOC }_{f p s o, t} \quad \forall f, f p s o, t
\end{aligned}
$$

Constraint (14) can be re-written as constraint (15), which can be further simplified by setting the positive variables $Z D_{f^{\prime}, f, f p s o, t}^{\text {field }}=b_{f^{\prime}, f p s o}^{o n} \cdot D F P S O C_{f, f p s o, t}^{\text {field }}$ and $Z D_{f \cdot f p s o, t}=b_{f, f p s o}^{o n} \cdot F P S O C_{f p s o, t}$ that yields constraint (16). Due to the bilinear terms involving binary variables $b_{f, \text { fpso }}^{\text {, }}$, we perform 
exact linearization, Glover ${ }^{43}$, for defining the variables $Z D_{f, f, f p s o, t}^{\text {field }}$ and $Z D_{f, f p s o, t}$ as in constraints (17)-(20) and (21)-(24), respectively, which in fact is equivalent to the convex hull of the corresponding disjunction of the nonlinear form.

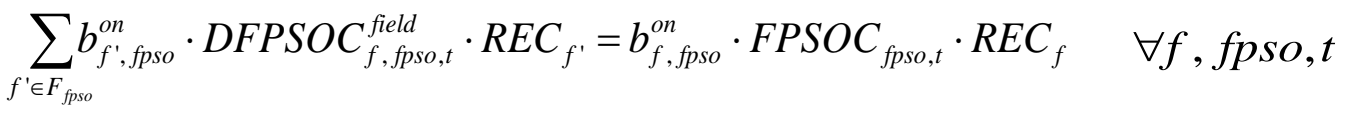

$$
\begin{aligned}
& \sum_{f^{\prime} \in F_{\text {frso }}} Z D_{f^{\prime}, f, f p s o, t}^{\text {field }} \cdot R E C_{f^{\prime}}=Z D_{f, \text { fpso,t }} \cdot R E C_{f} \quad \forall f, f p s o, t \\
& Z D_{f^{\prime}, f, f p s o, t}^{\text {field }}+Z D 1_{f^{\prime}, f, f p s o, t}^{\text {field }}=D F P S O C_{f, f p s o, t}^{\text {field }} \quad \forall f, \text { fpso, } t, f^{\prime} \in F_{f p s o} \\
& Z D_{f^{\prime}, f, f p s o, t}^{\text {field }} \leq U \cdot b_{f^{\prime}, f p s o}^{o n} \quad \forall f, \text { fpso, } t, f^{\prime} \in F_{f p s o} \\
& Z D 1_{f^{\prime}, f, f p s o, t}^{\text {fiel }} \leq U \cdot\left(1-b_{f^{\prime}, f p s o}^{o n}\right) \quad \forall f, \text { fpso, } t, f^{\prime} \in F_{f p s o} \\
& Z D_{f^{\prime}, f, f p s o, t}^{\text {field }} \geq 0, Z D 1_{f^{\prime}, f, f p s o, t}^{\text {field }} \geq 0 \quad \forall f, \text { fpso,t, } f^{\prime} \in F_{f p s o} \\
& Z D_{f, f p s o, t}+Z D 1_{f, f p s o, t}=F P S O C_{f p s o, t} \quad \forall f, f p s o, t \\
& Z D_{f, f p s o, t} \leq U \cdot b_{f, f p s o}^{o n} \quad \forall f, \text { fpso, } t \\
& Z D 1_{f, f p s o, t} \leq U \cdot\left(1-b_{f, f p s o}^{o n}\right) \quad \forall f, \text { fpso, } t \\
& Z D_{f, f p s o, t} \geq 0, Z D 1_{f, f p s o, t} \geq 0 \quad \forall f, \text { fpso,t }
\end{aligned}
$$

(iii) Operating Costs: The total operating expenses that correspond to ring-fence $r f$, eq. (25), are the operation costs corresponding to the total amount of liquid and gas produced in each time period t from that ring-fence.

$$
O P E R_{r f, t}=\delta_{t}\left[O C_{r f, t}^{l i q}\left(x_{r f, t}^{\text {tot }}+w_{r f, t}^{\text {tot }}\right)+O C_{r f, t}^{g a s} g_{r f, t}^{\text {tot }}\right] \quad \forall r f, t
$$

(iv) Revenues: The gross revenues (26) in each time period t for a ring-fence $r f$, are computed based on the total amount of oil produced and its selling price, where total oil flow rate in a time period $t$ for ring-fence $r f$, is calculated as the sum of the oil production rates over all the fields in 
that ring-fence, i.e. set $F_{r f}$, as given in equation (27). Given that all the fiscal terms are defined on the basis of total oil produced, for simplicity we only consider the revenue generated from the oil sales, which is much larger in general as compared to the revenue from gas. In practice, due to large transportation costs involved in shipping gas from offshore locations, it is usually reinjected or flared, if the gas revenue represent a small fraction of the oil revenues. However, extension to include the gas sales and/or fiscal terms associated is straightforward if the gas revenues are substantial.

$$
\begin{array}{ll}
R E V_{r f, t}=\delta_{t} \alpha_{t} x_{r f, t}^{\text {tot }} & \forall r f, t \\
x_{r f, t}^{\text {tot }}=\sum_{F_{r f}} x_{f, t} & \forall r f, t
\end{array}
$$

(iv) Total Contractor Share: The total contractor share that corresponds to ring-fence $r f$ in time period t is calculated in constraint (28) as the sum of contractor's profit oil share for that ringfence (after paying income tax) and the cost oil that it keeps to recover the expenses. The contractor needs to pay income-tax on its profit oil share. Therefore, the contractor's profit oil share before tax is the sum of contractor's profit oil share after tax and income tax paid as in constraint (29).

$$
\begin{array}{ll}
\text { TotalConSh }_{r f, t}=\text { ConSh }_{r f, t}^{\text {aftertax }}+\text { CO }_{r f, t} & \forall r f, t \\
\text { ConSh }_{r f, t}^{\text {beforetax }}=\text { ConSh }_{r f, t}^{\text {aftertax }}+\operatorname{Tax}_{r f, t} & \forall r f, t
\end{array}
$$

The contractor's share before tax in each time period $t$ is some fraction of the total profit oil during that period t for ring-fence $r f$. Note that we assume here that this fraction, which is called profit oil fraction $\left(f_{r f, i}^{p o}\right)$, is based on a decreasing sliding scale system, where $i$ is the index of the corresponding tier. The sliding scale system considered here is linked to the cumulative amount of oil produced $X c_{r f, t}$ by the end of that time period t from ring-fence $r f$, see Figure 5. The other variables for this type of sliding scale system could be for instance the contractor's IRR or R-factor. Therefore, for possible levels $i$ (i.e. tiers) of cumulative amount of oil produced by the end of time period t, the corresponding contractor's profit oil share, Figure 6, can be 
calculated from disjunction (30). In particular, variable $Z_{r f, i, t}$ in the disjunction will be true if cumulative oil produced in time period t for a ring-fence $r f$, lies between $L_{r f, i}^{\text {oil }}$ and $U_{r f, i}^{\text {oil }}$, i.e. tier $i$ is active in that time period $\mathrm{t}$ and corresponding profit oil fraction $f_{r f, i}^{p o}$ is used for calculating the contractor's profit oil share for ring-fence $r f$. This disjunction (30) can further be rewritten as integer and mixed-integer linear constraints (31)-(38) using the convex-hull formulation (Raman and Grossmann ${ }^{44}$ ). The solution time with the big-M formulation was much higher as compared to convex-hull formulation due to its weaker LP relaxation. Notice that the binary variables $Z_{r f, i, t}$ can also be represented as the SOS1 variables. However, we did not observe any specific improvements in the computational time with this alternate approach.

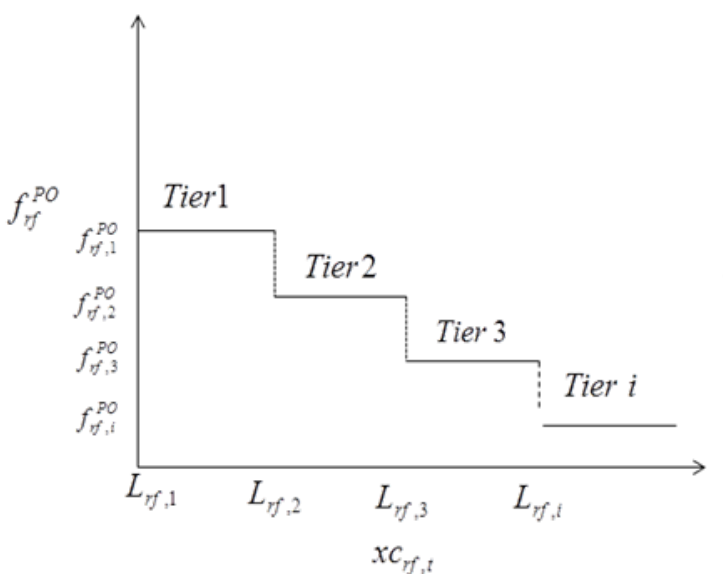

Figure 5: Sliding scale profit oil fraction

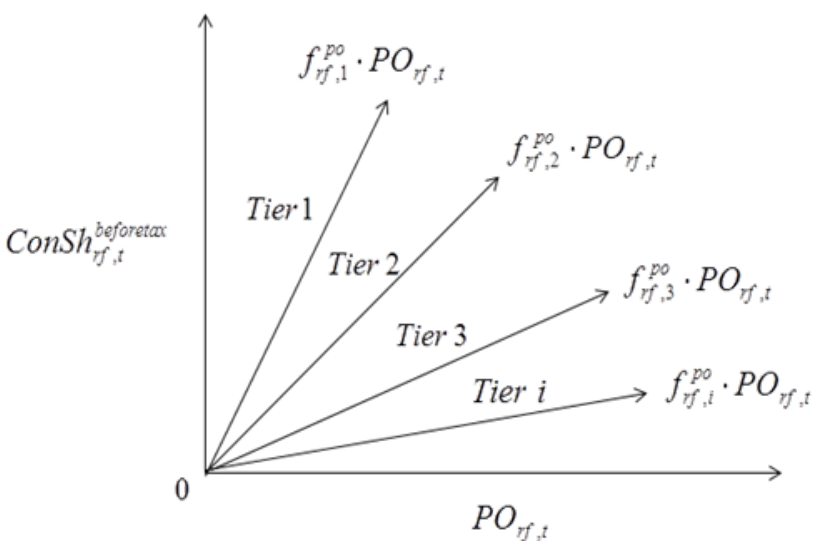

Figure 6: Contractor's share of profit oil

$$
\underset{i}{\vee}\left[\begin{array}{c}
Z_{r f, i, t} \\
\operatorname{ConSh}_{r f, t}^{\text {beforetax }}=f_{r f, i}^{P O} \cdot P O_{r f, t} \\
L_{r f, i}^{\text {oil }} \leq x C_{r f, t} \leq U_{r f, i}^{o i l}
\end{array}\right]
$$

$$
\forall r f, t
$$

ConSh $_{r f, t}^{\text {beforetax }}=\sum_{i} D$ ConSh $_{r f, i, t}^{\text {beforetax }}$

$$
\forall r f, t
$$

$P O_{r f, t}=\sum_{i} D P O_{r f, i, t}$

$$
\forall r f, t
$$

$X C_{r f, t}=\sum_{i} D x C_{r f, i, t}$

$$
\forall r f, t
$$




$$
\begin{array}{ll}
D_{\text {ConSh }}^{\text {beforetax }}=f_{r f, i}^{p o} \cdot D P O_{r f, i, t} & \forall r f, i, t \\
0 \leq D \operatorname{ConSh}_{r f, i, t}^{\text {beforetax }} \leq M \cdot Z_{r f, i, t} & \forall r f, i, t \\
0 \leq D P O_{r f, i, t} \leq M \cdot Z_{r f, i, t} & \forall r f, i, t \\
L_{r f, i}^{o i l} \cdot Z_{r f, i, t} \leq D x C_{r f, i, t} \leq U_{r f, i}^{o i l} \cdot Z_{r f, i, t} & \forall r f, i, t \\
\sum_{i} Z_{r f, i, t}=1 & \forall r f, t \\
Z_{r f, i, t} \in\{0,1\} &
\end{array}
$$

The cumulative amount of oil produced from a ring-fence $r f$ by the end of time period $t$ is calculated in constraint (39) as the sum of the cumulative amount of oil produced by that time period from all the fields associated to that ring-fence.

$$
x c_{r f, t}=\sum_{F_{r f}} x c_{f, t}^{\text {field }} \quad \forall r f, t
$$

The tax paid by the contractor on its profit oil share depends on the tax rate $\left(f_{r f, t}^{\operatorname{tax}}\right)$ as in constraint (40), which is a given parameter assumed to have a fixed value.

$$
\operatorname{Tax}_{r f, t}=f_{r f, t}^{\text {tax }} \cdot \text { ConSh }_{r f, t}^{\text {beforetax }} \quad \forall r f, t
$$

Constraint (41) states that total profit oil in time period t for a ring-fence $r f$, is the portion of the gross revenue that remains after subtracting the cost oil in that period t.

$$
P O_{r f, t}=R E V_{r f, t}-C O_{r f, t} \quad \forall r f, t
$$

The portion of the total revenues that Oil Company can claim for cost recovery, i.e. cost oil, is normally bounded above by the so-called "cost recovery ceiling” or "cost stop". Therefore, the cost oil in time period $t$ for a ring-fence $r f$, constraint (42), is calculated as the minimum of the cost recovery in that time period and maximum allowable cost oil (cost recovery ceiling). The cost recovery ceiling can be a fixed fraction $\left(0 \leq f_{r f, t}^{C R} \leq 1\right)$ of the gross revenue (Kaiser and Pulsipher $^{36}$ ) or it might be based on a sliding scale system. We assume here that the fraction $f_{r f, t}^{C R}$ is independent of project economics, i.e. a fixed parameter. Constraint (42) can further be rewritten as mixed-integer linear constraints (43)-(48). Notice that equation (42) can also be 
represented as a disjunction and its corresponding convex-hull formulation. However, based on our computational experience, we observed that using the convex-hull instead of the big-M constraints, (43)-(48), was much slower due to additional continuous variables that were required to model the problem, whereas the LP relaxation was almost identical.

$$
\begin{array}{ll}
C O_{r f, t}=\min \left(C R_{r f, t}, f_{r f, t}^{C R} \cdot R E V_{r f, t}\right) & \forall r f, t \\
C O_{r f, t} \leq C R_{r f, t}+M\left(1-b_{r f, t}^{c o}\right) & \forall r f, t \\
C O_{r f, t} \geq C R_{r f, t}-M\left(1-b_{r f, t}^{c o}\right) & \forall r f, t \\
C O_{r f, t} \leq f_{r f, t}^{C R} R E V_{r f, t}+M \cdot b_{r f, t}^{c o} & \forall r f, t \\
C O_{r f, t} \geq f_{r f, t}^{C R} R E V_{r f, t}-M \cdot b_{r f, t}^{c o} & \forall r f, t \\
C O_{r f, t} \leq C R_{r f, t} & \forall r f, t \\
C O_{r f, t} \leq f_{r f, t}^{C R} R E V_{r f, t} & \forall r f, t
\end{array}
$$

Cost recovery in time period t for a ring-fence $r f$, constraint (49), is the sum of capital and operating costs in that period $\mathrm{t}$ and cost recovery carried forward from previous time period $\mathrm{t}-1$. Any unrecovered cost (that is carried forward to the next period) in time period t for a ring-fence $r f$, is calculated as the difference between the cost recovery and cost oil in time period $t$ as given in constraint (50). Notice that constraints (43)-(50) state that any capital and operating costs that are not recovered in the form of cost oil due to cost recovery ceiling in any time period $t$ for a ring-fence $r f$, are carried forwarded to the next time period for the cost recovery purposes.

$$
\begin{array}{ll}
C R_{r f, t}=C A P_{r f, t}+O P E R_{r f, t}+C R F_{r f, t-1} & \forall r f, t \\
C R F_{r f, t}=C R_{r f, t}-C O_{r f, t} & \forall r f, t
\end{array}
$$

Constraints (1)-(13), (16)-(29), (31)-(41), (43)-(50) are linear and mixed-integer linear constraints that correspond to the fiscal part of the problem. Notice that we also have the nonnegativity restriction on all of the variables involved in these constraints, except NPV, as 
revenues, costs, tax, profit share, etc., that cannot be less than zero in any time period. These fiscal constraints can be included in either of the MINLP/MILP formulations in Gupta and Grossmann ${ }^{17}$ which correposnd to the reservoir constraints, field-FPSO flow constraints, FPSO capacity constraints, well drilling limitations and logic vonstraints.

The resulting oilfield infrastructure planning models with fiscal considerations (Models 1F, 2F and 3F) correspond to MINLP (for Models 1 and 2) or MILP (for Model 3) based on the type of reservoir profiles or their approximations used, which are described in Gupta and Grossmann ${ }^{17}$. Table 1 summarizes the main features of the proposed MINLP and MILP models with fiscal considerations. Notice that Models 1-3 are the simple NPV based models in Figure 1, while Models 1F-3F consider the fiscal aspects described above and associated trade-offs during planning.

Table 1: Comparison of the proposed oilfield planning models

\begin{tabular}{|c|c|c|c|}
\hline & Model 1F & Model 2F & Model 3F \\
\hline Model Type & MINLP & MINLP & MILP \\
\hline Oil Deliverability & $3^{\text {rd }}$ order polynomial & $3^{\text {rd }}$ order polynomial & Piecewise Linear \\
\hline WOR & $3^{\text {rd }}$ order polynomial & - & - \\
\hline GOR & $3^{\text {rd }}$ order polynomial & - & - \\
\hline wc & - & $4^{\text {th }}$ order polynomial & Piecewise Linear \\
\hline gc & - & $4^{\text {th }}$ order polynomial & Piecewise Linear \\
\hline Bilinear Terms & $\mathrm{N}^{*} \mathrm{x}$ & $\mathrm{N}^{*} \mathrm{x}$ & None \\
& $\mathrm{x}^{*}$ WOR & & \\
\hline MILP Reformulation & Not Possible & Possible & Reformulated MILP \\
\hline Fiscal Calculations & Yes & Yes & Yes \\
\hline
\end{tabular}

It should be noted that the fiscal part of the problem only involves calculations as in constraints (1)-(13), (16)-(29), (31)-(41), (43)-(50) for a given set of investment and operational decisions. In particular, all fiscal variables (cost oil, profit oil, tax etc.) are dependent variables that are pre-defined functions of costs and revenues (or flows) as can also be seen from Figure 1, and hence the total contractor's share is also a function of costs and revenues, eq. (51). However, including the fiscal part in the problem provides a way to make investment and operations decisions that are also optimal in terms of fiscal aspects.

TotalConSh $_{r f, t}=f\left(\operatorname{COST}_{r f, 1}, \operatorname{COST}_{r f, 2}, \ldots . . \operatorname{COST}_{r f, t} ; R E V_{r f, 1}, R E V_{r f, 2}, \ldots . . R E V_{r f, t}\right) \quad \forall r f, t(51)$

\section{Remarks:}


The proposed non-convex MINLP models (Model 1F and 2F) for offshore oilfield planning with fiscal rules involves nonlinear non-convex constraints due to reservoir profiles that can lead to suboptimal solutions when solved with an MINLP method that assumes convexity (e.g. branch and bound, outer-approximation; see Grossmann ${ }^{45}$ ). However, the MILP formulation (Model 3F) corresponds to Model 3 with fiscal constraints and can be solved to global optimality. The computational efficiency of the proposed MINLP and MILP models can be further improved by neglecting the timing of the piping investments. In particular, Model 1RF, 2RF and 3RF can be derived from corresponding Models 1R, 2R, and 3R, respectively, that are described in Gupta and Grossmann ${ }^{17}$ by including the fiscal constraints, (1)-(13), (16)-(29), (31)-(41) and (43)-(50).

In summary, Model 3RF, which is an MILP and derived from Model 3R, corresponds to the oilfield planning with fiscal considerations after binary reduction, is most efficient as it can be directly solved to global optimality in reasonable time as compared to other models described above. Moreover, its solution can also be used to fix the investment decisions in the MINLP models to obtain the near optimal solution of the original problem. Therefore, we use Model 3RF as a basis for the proposed reformulations, solution strategies and computational experiments presented in the next sections. Notice that these approaches are directly applicable to the other models, but it would be much expensive to either solve (e.g. Model 3F) or obtain good quality solutions (Model 1F, 1RF, 2F, 2RF) for these models directly as compared to Model 3RF as per the computational experience on the respective non-fiscal models in Gupta and Grossmann ${ }^{17}$.

The deterministic models with fiscal considerations proposed here are very generic, and can either be used for simplified cases (e.g. linear profiles for reservoir, fixed well schedule, single field site, etc.), or be extended to include other complexities such as uncertainties, or more details of the specific contracts.

\section{Deriving Specific Contracts from the Proposed Model}

In the previous section, we proposed a generic oilfield planning model with fiscal rules (Model 3RF). The model is an extension of the Model 3R (MILP) from our previous paper to include progressive PSA terms with ringfencing provisions that encapsulates a variety of contracts and fiscal terms that are used in practice. Therefore, the fiscal models for specific cases based on the 
type of contracts, fiscal terms and other provisions can be derived from this general formulation. For instance, we reduce the general model (Model 3RF) to a variety of specific cases as follows:

(a) No-ringfencing Provisions: The fiscal terms without ringfencing provisions can be trivially considered as the specific case of the proposed model with only 1 ringfence. In financial terms, it represents the consolidation of the fiscal calculations for the various fields at one place. Therefore, constraints (1)-(50) can be written without index for fingfence rf in this case. Moreover, as all the given fields belong to the same ringfence, the costs and revenues over various ringfences need not be disaggregated. In particular, constraints (6)-(24) reduce to the simple total capital cost equation (52) which is same as it was used in the models without fiscal calculations.

$$
\begin{aligned}
& C A P_{t}=\left[F C_{f p s o, t}^{F P S O} b_{f p s o, t}^{F P S O}+V C_{f p s o, t}^{l i q}\left(Q I_{f p s o, t}^{l i q}+Q E_{f p s o, t}^{l i q}\right)+V C_{f p s o, t}^{g a s}\left(Q I_{f p s o, t}^{g a s}+Q E_{f p s o, t}^{g a s}\right)\right] \\
& +\sum_{F_{r f}} \sum_{f p s o} F C_{f, f p s o, t} b_{f, f p s o, t}+\sum_{F_{r f}} F C_{f, t}^{\text {well }} I_{f, t}^{\text {well }} \quad \forall t
\end{aligned}
$$

(b) Concessionary System: The fiscal rules in a typical concessionary system can be considered as the specific case of PSA where we do not have any cost oil recovery limit and profit oil share. Therefore, only royalties, cost deduction and taxes are involved. Royalties can be calculated as a certain fraction ( $f_{r f, t}^{\text {Royal }}$ ) of the gross revenues, i. e. eq. (53). There are no cost ceiling provisions; and therefore, cost oil ceiling fraction is one in equation (42) (i.e. $f_{r f, t}^{C R}=1$ ), which yields equation (54). Notice that it allows to consider the total oil produced in a given year to be recovered for the capital and operating expenses after paying royalty. Equation (54) can further be rewritten as mixed-integer linear constraints similar to (43)-(48) where $f_{r f, t}^{C R}=1$. Notice that the cost recovery term $C R_{r f, t}$ used in eq. (54) has the same definition as in PSA model described earlier. Therefore, it can be represented by the constraints (49)-(50). The remaining part of the oil after royalties and cost oil becomes profit, eq. (55).

$$
\begin{aligned}
& \text { Royalty }_{r f, t}=f_{r f, t}^{\text {royal }} R E V_{r f, t} \quad \forall r f, t \\
& C O_{r f, t}=\min \left(C R_{r f, t}, R E V_{r f, t}\right) \quad \forall r f, t \\
& P O_{r f, t}=R E V_{r f, t}-\text { Royalty }_{r f, t}-C O_{r f, t} \quad \forall r f, t
\end{aligned}
$$


In addition, due to the absence of profit oil split layer in the fiscal calculation (Figure 2), for concessionary system, the contractor's share before tax can be set as equal to the profit oil, equation (56), which corresponds to the profit oil fraction as one, $\left(f_{r f, i, t}^{\mathrm{PO}}=1\right)$. Therefore, disjunction (30) is not required. The company needs to pay tax on its profit, eq. (57), where an effective tax rate may involve income tax and a specific profit tax, eq. (58), which are assumed to have a fixed value. The resulting tax is used to calculate the contractor's after tax share in eq. (59).

$$
\begin{array}{lr}
\text { ConSh }_{r f, t}^{\text {beforetax }}=P O_{r f, t} & \forall r f, t \\
\operatorname{Tax}_{r f, t}=f_{r f, t}^{\text {eff }, \text { taxrate }} \text { ConSh }_{r f, t}^{\text {beforetax }} & \forall r f, t \\
f_{r f, t}^{\text {eff,taxrate }}=f_{r f, t}^{\text {tax }}+f_{r f, t}^{\text {profit tax }} & \forall r f, t \\
\text { ConSh }_{r f, t}^{\text {aftertax }}=\text { ConSh }_{r f, t}^{\text {beforetax }}-\text { Tax }_{r f, t} & \forall r f, t
\end{array}
$$

Notice that a particular concessionary system can also have a sliding scale royalty rates and/or sliding scale profit tax rates to penalize the production over a certain threshold. However, including those fiscal considerations is straightforward based on the modeling approach presented in the previous section for profit oil share in a typical PSA.

(c) Regressive fiscal terms: It can be considered as a specific case of the progressive fiscal terms with only one tier. In particular, disjunction (30) and its corresponding reformulation (31)-(38) is not required in the model. Therefore, the contractor's share in the profit oil can directly be written in terms of the given profit oil fraction for ringfence $r f$ without index for tier $i$, constraint (60). Notice that since the binary variables corresponding to the disjunction are eliminated from the model for regressive fiscal terms, the model is likely to solve much faster than the progressive fiscal terms.

$$
\text { ConSh }_{r f, t}^{\text {beforetax }}=f_{r f}^{p o} \cdot P O_{r f, t} \quad \forall r f, t
$$

(d) Different sliding scale variables: The variables that define the tier structure for sliding scale can be contract specific. For instance, cumulative oil produced, R-factor or IRR. Therefore, a sliding scale variable $S V_{r f, t}$ for the fiscal system of interest can be used in disjunction (30) that yields disjunction (61), with its corresponding definition in eq. (62). Notice that depending on the definition of the sliding scale variable $S V_{r f, t}$ in eq. (62), there is the 
possibility that additional nonlinearities be introduced in the model, e.g. IRR as a sliding scale variable.

$$
\begin{aligned}
& \underset{i}{\vee}\left[\begin{array}{l}
Z_{r f, i, t} \\
\operatorname{ConSh}_{r f, t}^{\text {beforetax }}=f_{r f, i}^{P O} \cdot P O_{r f, t} \\
L_{r f, i}^{\text {oil }} \leq S V_{r f, t} \leq U_{r f, i}^{o i l}
\end{array}\right] \quad \forall r f, t \\
& S V_{r f, t}=f_{r f, t}\left(x c_{r f, t}, \operatorname{COST}_{r f, t}, R E V_{r f, t}, \ldots\right) \quad \forall r f, t
\end{aligned}
$$

In some cases, for instance sliding scale royalties where average daily oil production is the sliding scale variable, higher royalty rates are only applicable on the oil production rate that is above the given threshold value in each year, i.e. incremental sliding scale. Therefore, an effective overall royalty should be used in disjunction (61) for each tier i in each time period $t$ instead of higher royalty rate on the total oil production. This situation mainly occurs in the concessionary systems.

\section{Discussions:}

1. Including fiscal rules in a simple NPV based development planning models are traditionally assumed to be very expensive. However, this may not always be the case. For instance regressive (only 1 tier) fiscal terms may improve the computational performance of the model without any fiscal terms (e.g. regressive Model 3RF vs. Model 3R, see Table 9), or at least perform in the similar way. The progressive fiscal terms (tier structure as the disjunction in (30)) are usually the ones most responsible for increasing the computational time when we include the fiscal terms (see sections 7.2.1 and 7.3.1). This is due to the additional binary variables and resulting weak relaxation, as good bounds on the revenue, cost oil, profit oil for each time period are not known a priori. However, due to the importance of explicitly considering the fiscal aspects for planning optimization (see sections 7.1 and 7.2.1), it may be a worthwhile effort despite the increase in the solution time.

2. The model with ringfencing provisions is usually much more expensive to solve (see sections 7.2.2 and 7.3.2) than the model without any ringfence, as binary variables for tiers as in constraints (31)-(38) are required for each ringfence separately. In addition, the relaxation becomes even worse due to the cost disaggregation over each ringfence and additional binary variables as in constraints (6)-(24). Therefore, the computational efficiency of the fiscal 
model with many ringfences will rely on the efficiency of solving the model without any ringfence or just with few ringfences.

3. Concessionary or PSA fiscal system should have similar computational complexity as the solution time is associated to the progressive (tier) vs. regressive terms and ringfencing provisions that can be part of either of these contracts. For example, a regressive PSA model can be orders of magnitude faster than a progressive Concessionary system.

4. Although the proposed Model $3 R F$ is a general formulation, the computational time requirements may vary significantly depending on the variables that define tiers in disjunction (30). Furthermore, additional nonlinearities may be introduced in some cases, for instance the IRR as a sliding scale variable, that may require expensive global optimization based approaches for solving the resulting non-convex MINLP model. However, these rules are not very popular in practice.

\section{Computational Strategies}

In this section, we propose some reformulation/approximation techniques and solution strategies to overcome the computational expense that can arise from incorporating the fiscal part in planning, specifically the models where progressive fiscal terms are present. Notice that the proposed approaches and results are presented taking Model 3RF (MILP) as a basis, where tiers are defined on the basis of cumulative oil produced for profit oil share, disjunction (30), that are widely used in practice. However, these approaches can directly be extended to other models that are proposed and a different sliding scale variable. Notice also that the proposed strategies are independent of ringfencing provisions.

\section{Reformulation/Approximation Techniques}

The following reformulation/approximation techniques in the proposed Model 3RF can improve its computational performance significantly:

\section{(i) Logic Constraints and Valid Inequalities:}

The additional logic constraints (63) and (64) can be included in Model 3RF if the sliding scale variable is a monotonically increasing function as time evolves, e.g. cumulative oil produced. In particular, constraints (63) ensure that once tier i is active in current period t, earlier tiers (i'< i) 
cannot be active in the future. Similarly, constraints (64) state that higher tiers (i’> i) cannot to be active before time period $\mathrm{t}$ if tier $\mathrm{i}$ is active in that period.

$$
\begin{array}{ll}
Z_{r f, i, t} \Rightarrow \bigwedge_{\tau=t}^{T} \neg Z_{r f, i^{\prime}, \tau} & \forall r f, i, i^{\prime}<i, t \\
Z_{r f, i, t} \Rightarrow \bigwedge_{\tau=1}^{t} \neg Z_{r f, i^{\prime}, \tau} & \forall r f, i, i^{\prime}>i, t
\end{array}
$$

These logic constraints (63) and (64) can be expressed as integer linear inequalities, (65) and (66), respectively, (Raman and Grossmann ${ }^{46}$ ).

$$
\begin{array}{ll}
Z_{r f, i, t}+Z_{r f, i^{\prime}, \tau} \leq 1 & \forall r f, i, i^{\prime}<i, t, t \leq \tau \leq T \\
Z_{r f, i, t}+Z_{r f, i^{\prime}, \tau} \leq 1 & \forall r f, i, i^{\prime}>i, t, 1 \leq \tau \leq t
\end{array}
$$

In addition, we derive the following valid inequalities (67), see Appendix A (Proposition 1) for derivation, that can also be included in Model 3RF where cumulative oil produced is the sliding scale variable. The LHS of the inequality represents the cumulative contractor share in the profit oil by the end of time period $t$ in terms of the oil volume, where $\alpha_{t}$ is the price of oil. Since, profit oil in a given year, eq. (41), is the difference of total oil produced in that year less cost oil that contractor used to recover its costs. Therefore, the RHS in (67) corresponds to an upper bound on the cumulative contractor's share in the cumulative profit oil by the end of time period t based on the sliding scale profit oil share and cost oil that has been recovered. In particular, the first term in RHS of inequality (67) accounts for the amount of the cumulative oil that contractor can receive by the end of time period $t$ if tier $\mathrm{i}$ is active in the current time period t, based on the given tier thresholds without considering the impact of the cost oil. On the other hand, the second term in RHS is used to include the impact of cost oil recovery in the profit oil calculation to provide the tighter bound on cumulative contractor's share, where profit oil fraction of the last tier $f_{r f, i^{\text {end }}}^{\text {PO }}$ with minimum value is used so that it yields a valid upper bound for any tier i. Notice that these inequalities act as tight dynamic bounds on the cumulative contractor share that appears in the objective function for the corresponding value of the cumulative oil produced by the end of current year t. Therefore, this leads to a much tighter formulation than Model 3RF. 


$$
\begin{array}{cc}
\sum_{\tau \leq t}\left(\text { Contsh }_{r f, \tau}^{\text {beforetax }} / \alpha_{\tau}\right) \leq \sum_{i^{\prime}=1}^{i^{\prime} \leq i}\left(f_{r f, i^{\prime}}^{P O}-f_{r f, i^{\prime}-1}^{P O}\right) \cdot\left(x C_{r f, t}-L_{r f, i^{\prime}}\right)-f_{r f, i^{\text {end }}}^{P O} & \cdot \sum_{\tau \leq t}\left(C O_{r f, \tau} / \alpha_{\tau}\right) \\
& \forall r f, i, t
\end{array}
$$

We observed more than threefold improvement in the fullspace solution time with these additional mixed-integer linear constraints and valid inequalities, i.e. constraints (65)-(67) in Model 3RF, which we refer Model 3RF-L. This is due to the improved relaxation and significant reduction in the total number of nodes needed in the branch and bound search tree.

Notice that the same logic constraints (65)-(66) can be used for any other problem where sliding scale variable is monotonically increasing function as time progresses. A different set of logic constraints can be derived for a particular case of interest where this condition does not hold. Moreover, it is straightforward to derive similar inequalities (67) for other tier variables (e.g. daily oil produced), see Appendix A (Proposition 2). The general rule is that as long as we can represent the contractor's share (or cumulative one) as a direct fraction of gross revenues in the current period (or cumulative revenue) and the sliding scale variable is the daily oil produced (or cumulative oil), it is easy to generate similar inequalities. However, in some cases like with the IRR might require additional effort.

\section{(ii) Alternate formulation: Sliding scale Fiscal Rules without Binary Variables}

Model 3RF, that relies on disjunction (30) and corresponding binary variables to represent the sliding scale fiscal terms, usually becomes expensive to solve for the large instances. These instances may still be intractable even after we include the above logic constraints and valid inequalities. Therefore, in this section we present an alternative formulation of development planning Model 3RF with progressive fiscal terms that does not use disjunctions to represent the tier structure. Notice that although we consider the cumulative oil produced as the sliding scale variable, but the reformulation can also be used for a variety of other sliding scale variables.

In particular, the proposed reformulation Model 3RI is equivalent to the Model 3RF with valid inequalities described above (67), without considering the constraints (31)-(38) that correspond to the disjunction (30). The alternate model Model 3RI may yield the optimal solution to a typical concessionary system or some special cases of PSAs, for which the valid inequalities (67) reduce to the simpler ones, (see Appendix B for more details).

However, for the general case of progressive PSA that has cost oil limit provisions, the proposed Model 3RI yields the relaxation of the original disjunctive Model 3RF as constraints 
(31)-(38) are not present. Therefore, we outline the following two possibilities to use the alternate model for generic PSA fiscal terms:

\section{Case 1: Relaxed Model (Model 3RI)}

In this case, the valid inequalities are directly used in Model 3RF as described earlier, i.e. constraints (67) in place of constraints (31)-(38) that correspond to the disjunction (30). This yields a relaxed solution to the original problem, and therefore an upper bound. However, its solution can be used to generate a lower bound by fixing the discrete decisions in the original model. Furthermore, this model can be used in either a bi-level decomposition, disjunctive branch and bound, or branch and cut solution algorithm to close the gap between the upper and lower bounds. In general, this relaxed model provides very tight bounds, and good discrete decisions in orders of magnitude less time than the disjunctive formulation used for sliding scales in Model 3RF.

\section{Case 2: Approximate Model (Model 3RI-A)}

In this case, the valid inequalities (67) are defined in Model 3RI such that they yield an approximate solution to the original problem, i.e. these are replaced with constraints (68). Notice that the inequalities (67) and (68) that are used in Models 3RI and 3RI-A, respectively, only differ in the second term in RHS. In the first case (eq. 67), as we use the least value of this term $\left(f_{r f, i^{\text {rad }}}^{\text {po }}\right)$ for it to be valid for all tiers, so it turns out to be the relaxation. On the other hand, in eq.

(68) we use the highest value of this term $\left(f_{r, 1}^{\text {po }}\right)$ to approximate the initial tiers as close to reality as possible when costs are high yielding near optimal solutions. Since, Model 3RI-A is an approximate model, neither an upper or lower bound is guaranteed from this model, but in practice, it yields the solution within 2-3\% of accuracy based on our computational experiments. Moreover, its solution can be used to generate a near optimal solution to the original problem in orders of magnitude less time than the disjunctive approach used in Model 3RF. The detailed description of the correspondence between these two different set of inequalities, (67) vs. (68), and derivation of inequalities (68) is explained in Appendix C.

$$
\begin{gathered}
\sum_{\tau \leq t}\left(\text { Contsh }_{r f, \tau}^{\text {beforetax }} / \alpha_{\tau}\right) \leq \sum_{i^{\prime}=1}^{i^{\prime} \leq i}\left(f_{r f, i^{\prime}}^{P O}-f_{r f, i^{\prime}-1}^{P O}\right) \cdot\left(x C_{r f, t}-L_{r f, i^{\prime}}\right)-f_{r f, 1}^{P O} \cdot \sum_{\tau \leq t}\left(C O_{r f, \tau} / \alpha_{\tau}\right) \\
\forall r f, i, t
\end{gathered}
$$




\section{Remarks:}

1. The advantage of using Model 3RI and Model 3RI-A is that these are orders of magnitude faster to solve than other fiscal models relying on the disjunctive constraints, and even 3-4 times faster than solving the models without any fiscal terms (i.e. Model 3R) as observed by the computational experiments. The extreme instances of the oilfield planning problem with fiscal terms, i.e. progressive PSA with ringfencing, are solved in reasonable time using these alternate models which were intractable for Model 3RF.

2. Notice that the alternate Model 3RI and its approximation Model 3RI-A are defined for the tier structure that is assumed to be linked to the cumulative oil produced. Other sliding scale variables, e.g. daily oil produced, R-factor are also used in practice. The similar approaches as described in the paper can be explored to model these fiscal considerations without explicitly using disjunctions and corresponding binaries variables.

These reformulation/approximation techniques can be used for the other models directly. Tables 2 and 3 summarize all of the proposed models (MINLP and MILP) for oilfield development planning problem with and without fiscal considerations. In particular, Table 2 involves basic models 1,2 and 3 with their fiscal counterparts considering detailed investment timing for the pipeline connections. Whereas, Table 3 represents the respective reduced models that are obtained by removing a large fraction of binary variables that represent connection timings to improve the computational efficiency without significant loss in the solution quality.

Table 2: Comparison of the proposed oilfield planning models (detailed connections)

\begin{tabular}{|c|c|c|c|}
\hline & MINLP & MINLP & MILP \\
\hline Basic Model & Model 1 & Model 2 & Model 3 \\
\hline $\begin{array}{c}\text { Basic model with fiscal terms } \\
\text { (using Disjunctions (30)) }\end{array}$ & Model 1F & Model 2F & Model 3F \\
\hline $\begin{array}{c}\text { Basic model with fiscal terms } \\
\text { (using Disjunctions (30), Logic constraints (65)-(66) } \\
\text { and valid Inequalities (67)) }\end{array}$ & Model 1F-L & Model 2F-L & Model 3F-L \\
\hline $\begin{array}{c}\text { Basic model with fiscal terms } \\
\text { (no binary variables for sliding scales i.e. using only } \\
\text { valid Inequalities (eq. (67) for relaxed/exact model } \\
\text { or eq. (68) for approximate model)) }\end{array}$ & $\begin{array}{c}\text { Model 1I-A } \\
\text { (relaxed/exact) }\end{array}$ & $\begin{array}{c}\text { Model 2I-A } \\
\text { (relaxed/exact) }\end{array}$ & $\begin{array}{c}\text { Model 3I-A } \\
\text { (relaxed/exact) }\end{array}$ \\
\hline
\end{tabular}


Table 3: Comparison of the proposed oilfield planning models (neglecting piping investments)

\begin{tabular}{|c|c|c|c|}
\hline & MINLP & MINLP & MILP \\
\hline Basic Model with binary reduction & Model 1R & Model 2R & Model 3R \\
\hline $\begin{array}{l}\text { Basic model with binary reduction and fiscal terms } \\
\text { (using Disjunctions (30)) }\end{array}$ & Model 1RF & Model 2RF & Model 3RF \\
\hline $\begin{array}{c}\text { Basic model with binary reduction and fiscal terms } \\
\text { (using Disjunctions (30), Logic constraints (65)-(66) } \\
\text { and valid Inequalities (67)) }\end{array}$ & Model 1RF-L & Model 2RF-L & Model 3RF-L \\
\hline \multirow{2}{*}{$\begin{array}{l}\text { Basic model with binary reduction and fiscal terms } \\
\text { (no binary variables for sliding scales i.e. using only } \\
\text { valid Inequalities (eq. (67) for relaxed/exact model } \\
\text { or eq. (68) for approximate model)) }\end{array}$} & $\begin{array}{c}\text { Model 1RI } \\
\text { (relaxed/exact) }\end{array}$ & $\begin{array}{c}\text { Model 2RI } \\
\text { (relaxed/exact) }\end{array}$ & $\begin{array}{c}\text { Model 3RI } \\
\text { (relaxed/exact) }\end{array}$ \\
\hline & $\begin{array}{l}\text { Model 1RI-A } \\
\text { (approximate) }\end{array}$ & $\begin{array}{l}\text { Model 2RI-A } \\
\text { (approximate) }\end{array}$ & $\begin{array}{l}\text { Model 3RI-A } \\
\text { (approximate) }\end{array}$ \\
\hline
\end{tabular}

\section{Numerical Results}

In this section, we consider three instances of the oilfield planning problem with fiscal considerations where ringfencing provisions may or may not be present, and examine the efficiency of the proposed models and solution strategies.

\subsection{Instance 1}

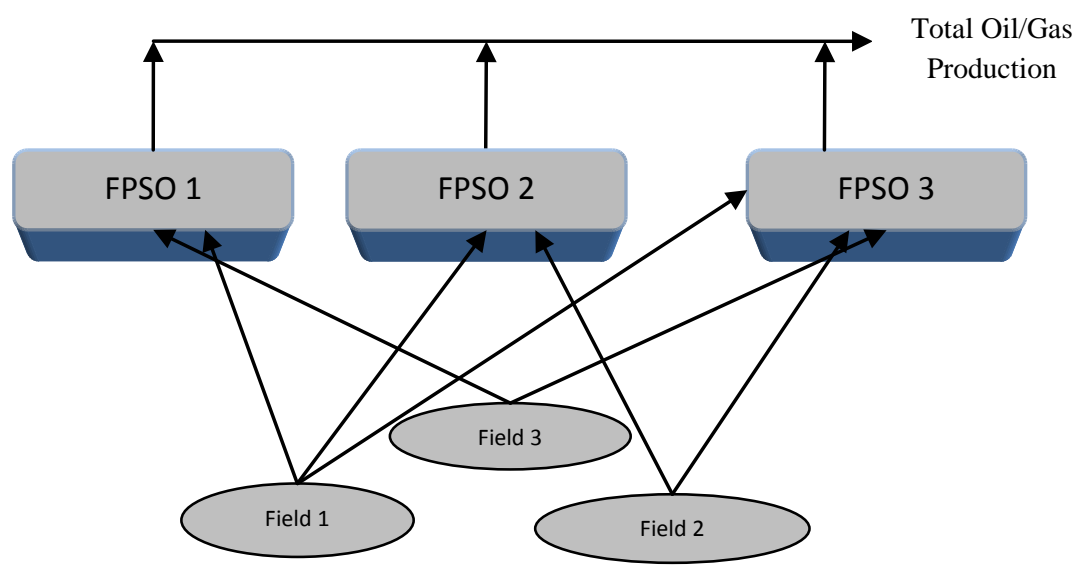

Figure 7: Instance 1 (3 Fields, 3 FPSO, 15 years), No Ringfencing

In this instance (Figure 7) we consider 3 oil fields that can be connected to 3 FPSOs with 7 possible connections among these fields and FPSOs. There are a total of 25 wells that can be drilled, and the planning horizon considered is 15 years, which is discretized into 15 periods of 
each 1 year of duration. Table 4 represents the data corresponding to the field sizes and their initial deliverability per well for a particular field-FPSO connection. There is a cost recovery ceiling of 50\% and 3 tiers that are defined for profit oil split between the contractor and the host government, and are linked to cumulative oil production as seen in Table 5 . This represents the fiscal terms of a typical progressive Production Sharing Agreement without ringfencing provisions.

Table 4: Field characteristics for instance 1

\begin{tabular}{|c|c|c|c|c|}
\hline \multirow{2}{*}{ Fields } & \multirow{2}{*}{$\begin{array}{c}\text { Field Size } \\
\text { (MMbbl) }\end{array}$} & \multicolumn{3}{|c|}{ Initial Oil derivability per well (kstb/d) } \\
\cline { 3 - 5 } & FPSO 1 & FPSO 2 & FPSO 3 \\
\hline Field 1 & 230 & 16 & 18 & 16 \\
\hline Field 2 & 280 & - & 18 & 20 \\
\hline Field 3 & 80 & 15 & - & 12 \\
\hline
\end{tabular}

We need to determine which of the FPSO facilities is to be installed or expanded, in what time period, and what should be its capacity of oil, liquid and gas, to which fields it should be connected and at what time, and the number of wells to be drilled in each field during each time period. Other than these installation decisions, there are operating decisions involving the flowrate of oil, water and gas from each field in each time period. The problem is solved to maximize the NPV of the contractor's share after paying taxes, and corresponding optimal investment and operations decisions over the planning horizon.

Table 5: Sliding scale Contractor's profit oil share for instance 1

\begin{tabular}{|c|c|c|}
\hline Tiers & Cumulative Oil Produced & Contractor's Share in Profit Oil \\
\hline Tier 1 & $0-150 \quad$ MMbbl & $50 \%$ \\
\hline Tier 2 & $150-325 \mathrm{MMbbl}$ & $40 \%$ \\
\hline Tier 3 & $>325 \quad$ MMbbl & $20 \%$ \\
\hline
\end{tabular}

The models are implemented in GAMS 23.6.3 and run on Intel Core i7, 4GB RAM machine using CPLEX 12.2. The optimal solution of this problem is presented in Table 6, that corresponds to Model 3F involving detailed connections, suggests installing only FPSO 3 with a capacity of $300 \mathrm{kstb} / \mathrm{d}, 297.75 \mathrm{kstb} / \mathrm{d}$ and 161.90 MMSCF/d for oil, liquid and gas, respectively, at the beginning of year 1. It takes 3 years for this FPSO to be available for production. Fields 1 and 2 are connected to this FPSO at the beginning of year 4, where 7 wells are drilled in Field 1 and 6 wells are drilled in Field 2 to start the production. These fields are preferred compared to 
Field 3 due to their large sizes and deliverabilities. Liquid capacity of FPSO 3 facility is expanded by $103.93 \mathrm{kstb} / \mathrm{d}$ in year 5 that becomes available in year 6 due to 1 year of lead time involved. Field 3 that is smaller in size comes online at the beginning of year 6 when deliverability of fields 1 and 2 decreases, where 3 wells are drilled in this field with an additional well in year 9 when production goes down. There are no further expansions and well drillings after year 9. Notice that most of the investments occur in early stages of the project. The total NPV of this project is $\$ 1497.69 \mathrm{M}$ after paying government share.

Table 6: Optimal Installation and Drilling Schedule for instance 1

\begin{tabular}{|c|c|c|c|c|c|c|c|c|c|c|}
\hline Year & 1 & 2 & 3 & 4 & 5 & 6 & 7 & 8 & 9 & $10-15$ \\
\hline $\begin{array}{c}\text { Facility } \\
\text { Installations }\end{array}$ & $\begin{array}{c}\text { Install } \\
\text { FPSO3 }\end{array}$ & - & - & - & $\begin{array}{c}\text { Expand } \\
\text { FPSO3 }\end{array}$ & - & - & - & - & - \\
\hline Field 1 & - & - & - & $\begin{array}{c}\text { Drill } \\
7 \text { wells }\end{array}$ & - & - & - & - & - & - \\
\hline Field 2 & - & - & - & $\begin{array}{c}\text { Drill } \\
6 \text { wells }\end{array}$ & $\begin{array}{c}\text { Drill } \\
1 \text { well }\end{array}$ & $\begin{array}{c}\text { Drill } \\
2 \text { wells }\end{array}$ & - & - & - & - \\
\hline Field 3 & - & - & - & - & - & $\begin{array}{c}\text { Drill } \\
\text { 3 wells }\end{array}$ & - & - & $\begin{array}{c}\text { Drill } \\
1 \text { well }\end{array}$ & - \\
\hline
\end{tabular}

Figures 8-9 represent the total oil and gas flow rates for the FPSO facility during the planning horizon considered. Given that the timing of the particular tier activation depends upon the cumulative oil production for this instance (Table 5) Tier 2 becomes active after fifth year while Tier 3 is active after the eighth year involving less share in profit oil for contractor, see Figure 10.

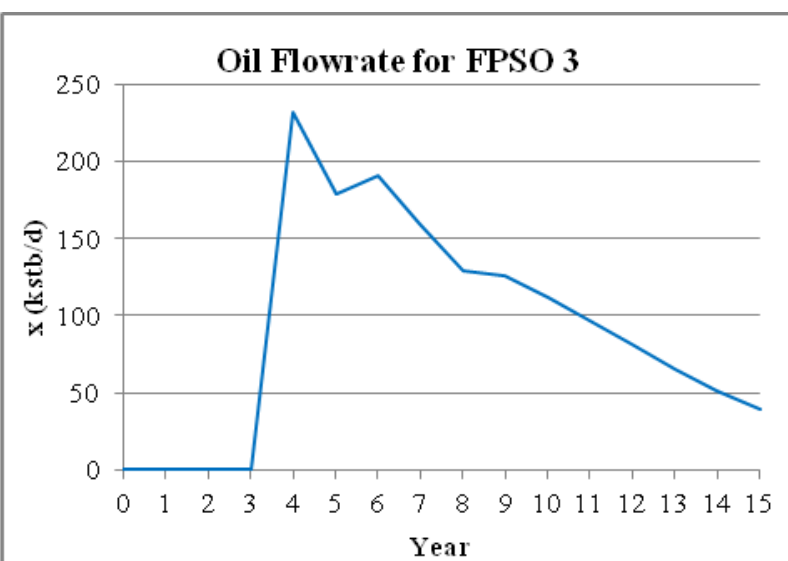

Figure 8: Total oil flowrate for FPSO 3

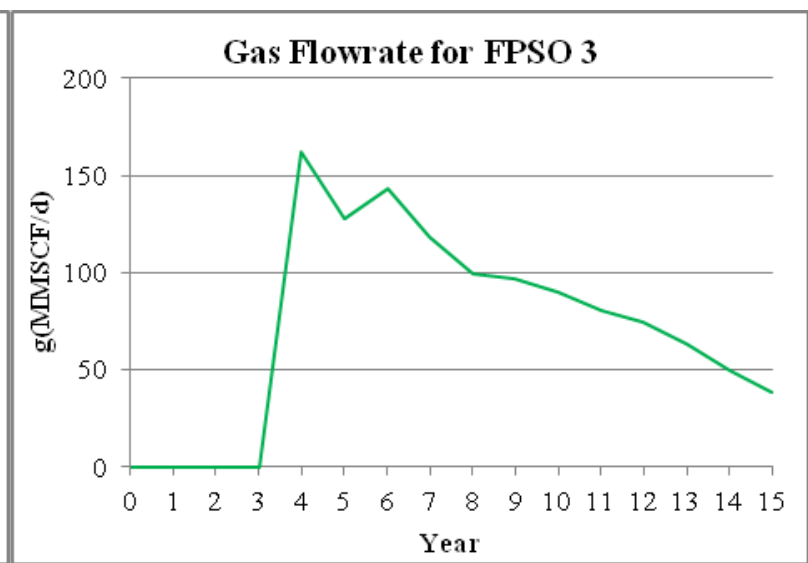

Figure 9: Total gas flowrate for FPSO 3 


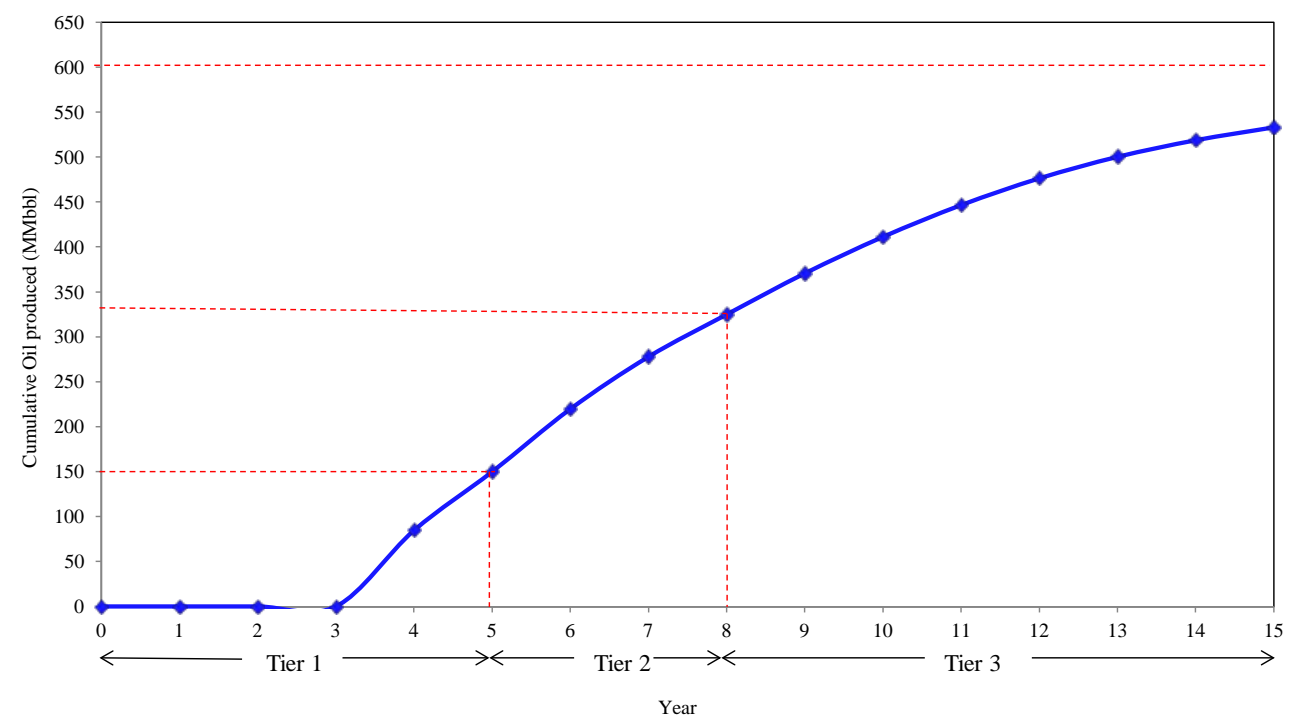

Figure 10: Cumulative Oil Produced vs. Timing of Tier activation

In contrast, the sequential approach that first maximizes NPV i.e. Model 3, without considering the impact of the fiscal terms, and then calculates the contractor share based on these decisions and fiscal rules, yields a very different solution. The optimum in this case suggests installing FPSO3 with a large capacity (oil 300 kstb/d, liquid 445.54 kstb/d and gas 211.65 MMSCF/d) at the beginning of the planning horizon without any future expansions. The drilling decisions are also front ended compared to the solution of the fiscal model, Model 3F. However, the total NPV of the contractor's share in the sequential case turns out to be $\$ 1362.67 \mathrm{M}$, which is significantly lower than the optimal solution (\$1497.69M) of the model with fiscal considerations (Model 3F). These results represent the optimistic nature of the sequential approach that tries to generate as much revenue as possible at the beginning of the planning horizon neglecting the trade-offs that are associated to the fiscal part. Therefore, it may lead to the decisions that can incur large losses in the long term after considering the impact of the fiscal calculations.

Table 7 compares the computational performance of the various models. In particular, Model 3RF which is obtained after binary reduction from Model 3F yields the same solution in an order of magnitude less time (337s vs. 3,359s), when solved to optimality. In contrast, solving the corresponding MINLP formulation Model 2F with BARON can only provide a solution having NPV of \$ $1198.44 \mathrm{M}$ with a $60 \%$ gap in more than 10 hours. Moreover, we observe that solving Model 2F directly with DICOPT requires a good initialization due to the additional binary variables and constraints that are added in this fiscal model compared to Model 
2. Therefore, the optimal solution from corresponding MILP formulations (Model 3F and Model 3RF) provides a way to obtain a near optimal solution of the original Model 2F. We fixed the design decisions in Model 2F from the optimal solution of Model 3RF and solved the resulting NLP problem that yields an NPV of \$1496.26 M, which shows that the accuracy of the MILP solution is within $0.1 \%$ of the MINLP formulation. Therefore, the proposed MILP formulations are computationally efficient and provide near optimal solutions. In the next section, we will use these MILP models as the basis and examine the performance of the proposed computational strategies for the larger instances.

Table 7: Comparison of the computational performance of various models for instance 1

\begin{tabular}{|l|c|r|r|r|r|r|}
\hline \multicolumn{1}{|c|}{ Model } & \multicolumn{1}{c|}{ Solver } & $\begin{array}{c}\text { \# of } \\
\text { constraints }\end{array}$ & $\begin{array}{c}\text { \# of continuous } \\
\text { variables }\end{array}$ & $\begin{array}{c}\text { \# of discrete } \\
\text { variables }\end{array}$ & $\begin{array}{c}\text { NPV } \\
\text { (\$Million) }\end{array}$ & Time (s) \\
\hline Model 2F (MINLP) & BARON 9.0.6 & 3,557 & 2,236 & 345 & $\begin{array}{r}1,198.44 \\
\text { (<60\% gap) }\end{array}$ & $>36,000$ \\
\hline Model 3F (MILP) & CPLEX 12.2 & 5,199 & 3,668 & 399 & $1,497.69$ & 3,359 \\
\hline Model 3RF (MILP) & CPLEX 12.2 & 5,147 & 3,570 & 322 & $1,497.69$ & 337 \\
\hline
\end{tabular}

\subsection{Instance 2:}

\subsubsection{PSA without ringfencing provisions for Instance 2}

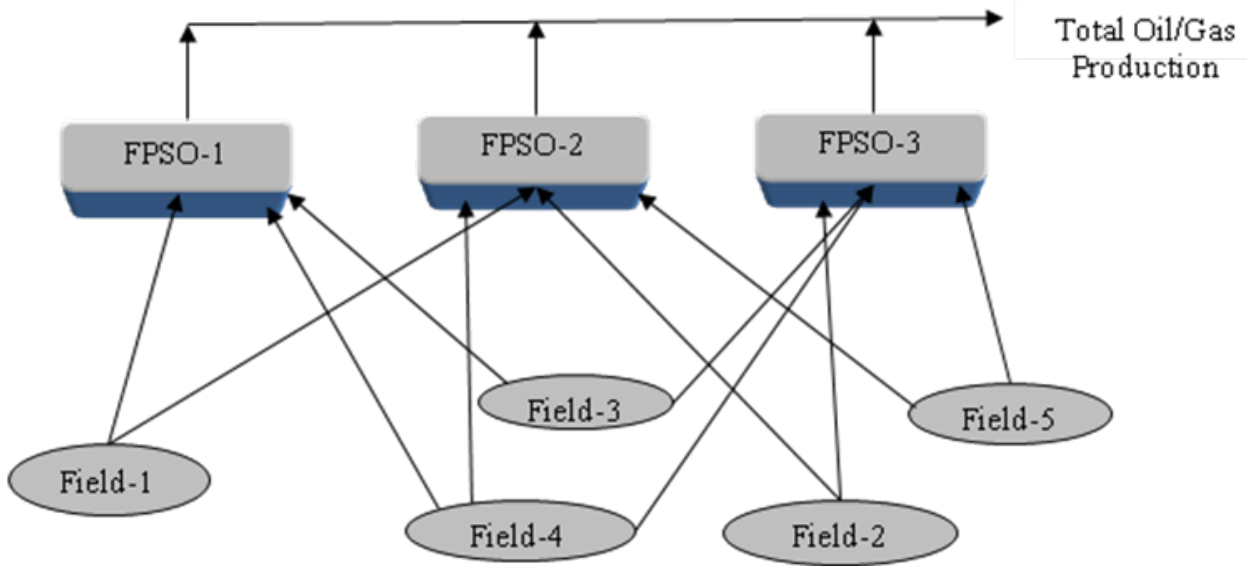

Figure 11: Instance 2 involving 5 Fields, 3 FPSO, 20 years, No ringfences

In this instance, we consider 5 oilfields that can be connected to 3 FPSOs with 11 possible connections, see Figure 11. There are a total of 31 wells that can be drilled in these 5 fields, and the planning horizon considered is 20 years. There is a cost recovery ceiling of 50\% and 4 tiers (see Fig. 3) that are defined for profit oil fraction between the contractor and host government based on the cumulative oil production. The problem is solved to maximize the NPV 
of the contractor's share after paying taxes and the corresponding optimal investment/operations decisions.

Table 8 compares the performance of the MILP (Model 3F) involving detailed connections and reduced MILP model (Model 3RF) that are the extension of the Models 3 and 3R, respectively, with progressive PSAs. The models are implemented in GAMS 23.6.3 and run on Intel Core i7, 4GB RAM machine using CPLEX 12.2. We can observe that there is significant increase in the computational time with fiscal consideration for the MILP formulation Model 3F with this larger instance, which takes more than 10 hours with a $14 \%$ of optimality gap as compared to the reduced MILP model (Model 3RF), which terminates the search with a 2\% gap in reasonable time.

Table 8. Computational Results for Instance 2 (Model 3F vs. Model 3RF)

\begin{tabular}{|l|r|r|r|r|r|r|}
\hline \multicolumn{1}{|c|}{ Model } & \multicolumn{1}{c|}{$\begin{array}{c}\text { \# of } \\
\text { constraints }\end{array}$} & $\begin{array}{c}\text { \# of continuous } \\
\text { variables }\end{array}$ & $\begin{array}{c}\text { \# of discrete } \\
\text { variables }\end{array}$ & $\begin{array}{c}\text { NPV } \\
\text { (\$Million) }\end{array}$ & Time (s) & $\begin{array}{c}\text { Optimality } \\
\text { Gap }\end{array}$ \\
\hline Model 3F & 9,474 & 6,432 & 727 & $2,183.63$ & $>36,000$ & $<14 \%$ \\
\hline Model 3RF & 9,363 & 6,223 & 551 & $2,228.94$ & 1,164 & $<2 \%$ \\
\hline
\end{tabular}

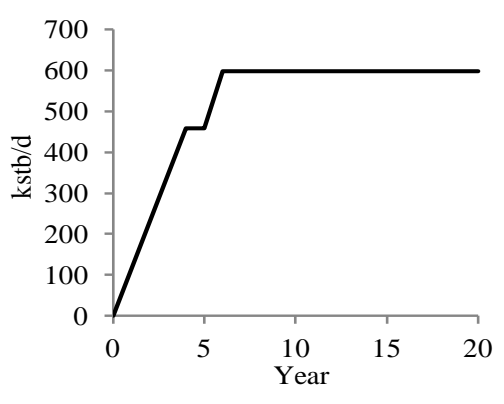

(a) Liquid capacity

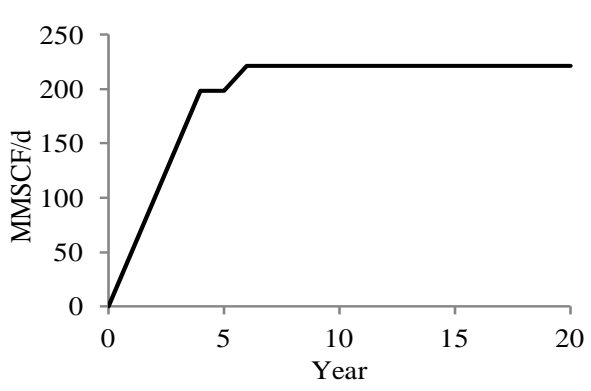

(b) Gas capacity

Figure 12. Optimal liquid and gas capacities of FPSO 3 facility for Instance 2

The optimal solution from Model 3RF suggests installing 1 FPSO facility (FPSO3) with expansions in the future (see Fig. 12), while Fig. 13 represents the well drilling schedule for this example. The tiers 2, 3 and 4 for profit oil split become active in years 6, 8 and 12, respectively, based on the cumulative oil production profile during the given planning horizon. Notice that the optimal solution of this problem fails to develop field 1, which is not intuitive. The reason for not developing field 1 is that the size of the field 1 is quite small as compared to the other fields and the superstructure we consider does not allow connecting field 1 to FPSO 3, which is the only FPSO that is installed. Therefore, based on the superstructure and field size, it is not worth to install an additional FPSO to produce from this field after paying government share. In contrast, 
the solution from the sequential approach suggests exploring field 1 as well since it is worth in that case to install 2 small FPSO facilities and also produce from field 1 given that the trade-offs due to fiscal rules are neglected. The total NPV of the contractor's share in this case is lower than the optimal solution of Model 3RF (\$1,914.71M vs. \$2,228.94M ). Therefore, we can observe that incorporating fiscal terms within development planning can yield significantly different investment and operations decisions compared to a simple NPV based optimization.

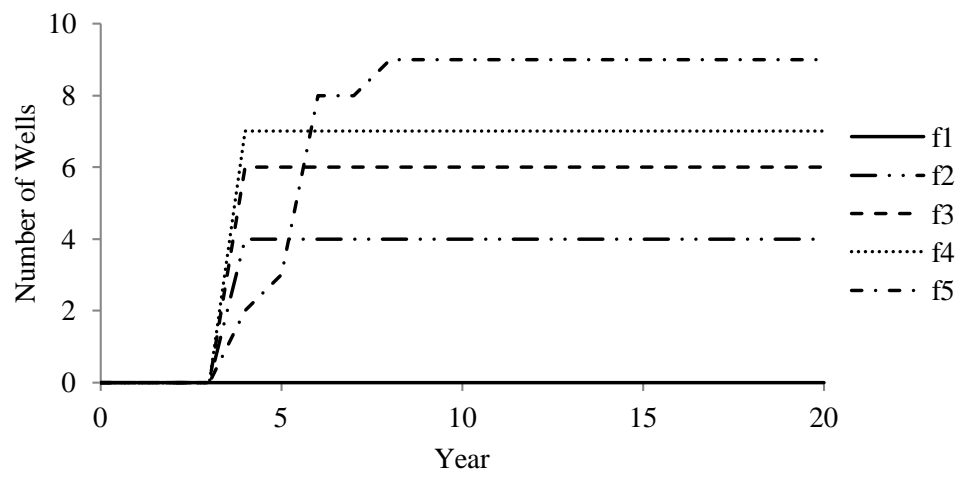

Figure 13. Optimal well drilling schedule for Instance 2

Note that fiscal terms without tier structure, for instance fixed percentage of profit share, royalty rates, often reduces the computational expense of solving the deterministic model directly without any fiscal terms instead. Surprisingly, the problem with flat $35 \%$ of the profit share of contractor is solved in 73s which is even smaller than the solution time for deterministic case without any fiscal terms (190s). On the other hand, the problem with 2 tiers instead of 4 as considered above is solved in 694s which is more than the model without fiscal terms and less than the model with 4 tiers as can be seen in Table 9. Therefore, the increase in computational time while including fiscal rules within development planning, is directly related to the number of tiers (levels) that are present in the model to determine the profit oil shares or royalties.

Table 9. Comparison of number of tiers vs. solution time for Model 3RF

\begin{tabular}{|c|r|}
\hline \# of tiers & \multicolumn{1}{|c|}{ Time (s) } \\
\hline 4 & 1,164 \\
\hline 2 & 694 \\
\hline 1 & 73 \\
\hline No fiscal rules & 190 \\
\hline
\end{tabular}


Table 10 compares the further improvements in the solution time for Model 3RF (1,164s) after using the reformulation/approximation techniques and strategies that are proposed. In particular, the tighter formulation Model 3RF-L that is obtained after including logic constraint and valid inequalities, (65)-(67), is solved in one fourth of the time than Model 3RF. Notice that these MILP models are solved with a 2\% of optimality tolerance yielding a slightly different objective values for Model 3RF and Model 3RF-L. Model 3RI, which relaxes the disjunction (30), can be solved more than 20 times faster than the original Model 3RF. Although the solution obtained is a relaxed one (upper bound of 2,591.10), it gives the optimal investment decisions that result in the same solution as we obtained from solving Model 3RF directly. The approximate version of this model Model 3RI-A, takes only 82s as compared to Model 3RF (1164s) and yields the optimal solution after we fix the decisions from this model in the original one. Notice that the quality of the approximate solution itself is very good ( $1.5 \%$ accurate) and both relaxed/approximate models are even $\sim 3$ times faster than the model without any fiscal terms (Model 3R) that takes 190s.

Table 10. Results for Instance 2 after using various solution strategies

\begin{tabular}{|l|r|r|r|r|r|r|}
\hline \multicolumn{1}{|c|}{ Model } & $\begin{array}{c}\text { \# of } \\
\text { constraints }\end{array}$ & $\begin{array}{c}\text { \# of } \\
\text { continuous } \\
\text { variables }\end{array}$ & $\begin{array}{c}\text { \# of } \\
\text { discrete } \\
\text { variables }\end{array}$ & $\begin{array}{c}\text { NPV } \\
\text { (\$Million) }\end{array}$ & $\begin{array}{c}\text { NPV after } \\
\text { fixing decisions } \\
\text { in Model 3RF } \\
\text { (\$Million) }\end{array}$ & \multicolumn{1}{|c|}{ Time (s) } \\
\hline Model 3RF & 9,363 & 6,223 & 551 & $2,228.94$ & - & -164 \\
\hline Model 3RF-L & 11,963 & 6,223 & 551 & $2,222.40$ & - & 275 \\
\hline Model 3RI-A & 8,803 & 5,903 & 471 & $2,197.63$ & $2,228.94$ & 82 \\
\hline Model 3RI & 8,803 & 5,903 & 471 & $2,591.10$ & $2,228.94$ & 48 \\
\hline
\end{tabular}

\subsubsection{PSA with ringfencing provisions for Instance 2}

In this case, we consider two ringfences for the above Instance 2 (see Figure 4) where progressive PSA terms are defined for each of these ringfences separately. Based on the computational performance of the Model 3RF as compared to Model 3F in the previous case, we only show the results for Model 3RF, which is the most efficient.

Table 11 compares the results for various models for this case. We can observe that including ringfencing provisions makes Model 3RF expensive to solve ( $>10 \mathrm{hrs}$ ), compared to the previous instance without any ringfences that required only 1,164s. This is due to the additional binary variables that are required in the model for each of the two ringfences, their trade-offs and FPSO cost disaggregation. In contrast, since Models 3RI and 3RI-A do not need 
binary variable for the sliding scale in disjunction (30), they solve much faster than Model 3RF (>300 times faster) and Model 3RF-L ( $\sim 30$ times faster). Notice that even after including ringfencing provisions, these two models are faster than the simple NPV based Model 3R. This is due to the trade-off from the fiscal part in the simple NPV based model without binary variables for the sliding scale.

Table 11. Results for Instance 2 with ringfencing provisions

\begin{tabular}{|l|r|r|r|r|r|r|r|}
\hline \multicolumn{1}{|c|}{ Model } & $\begin{array}{c}\text { \# of } \\
\text { constraints }\end{array}$ & $\begin{array}{c}\text { \# of } \\
\text { continuous } \\
\text { variables }\end{array}$ & $\begin{array}{c}\text { \# of } \\
\text { discrete } \\
\text { variables }\end{array}$ & $\begin{array}{c}\text { NPV } \\
\text { (\$Million) }\end{array}$ & $\begin{array}{c}\text { NPV after } \\
\text { fixing } \\
\text { decisions in } \\
\text { Model 3RF } \\
\text { (\$Million) }\end{array}$ & Time (s) & $\begin{array}{c}\text { Optimality } \\
\text { gap } \\
\text { (\%) }\end{array}$ \\
\hline Model 3RF & 14,634 & 9,674 & 651 & $2,149.39$ & - & $>36,000$ & $<15.4 \%$ \\
\hline Model 3RF-L & 19,834 & 9,674 & 651 & $2,161.27$ & - & 3,334 & $<2 \%$ \\
\hline Model 3RI-A & 13,514 & 9,034 & 491 & $2,148.90$ & $2,142.75$ & 134 & $<2 \%$ \\
\hline Model 3RI & 13,514 & 9,034 & 491 & $2,533.06$ & $2,151.75$ & 112 & $<2 \%$ \\
\hline
\end{tabular}

Notice that Model 3RI and 3RI-A are solved here in one of the most generic forms of the fiscal terms where the solutions may not be the global optimal, but the relaxed Model 3RI, which provides a valid upper bound, also allows to compare the solution quality. The optimal NPV after ringfencing provisions is lower as compared to the earlier case without ringfencing provisions due to the additional restrictions it imposes on the revenue and cash flows.

\subsection{Instance 3}

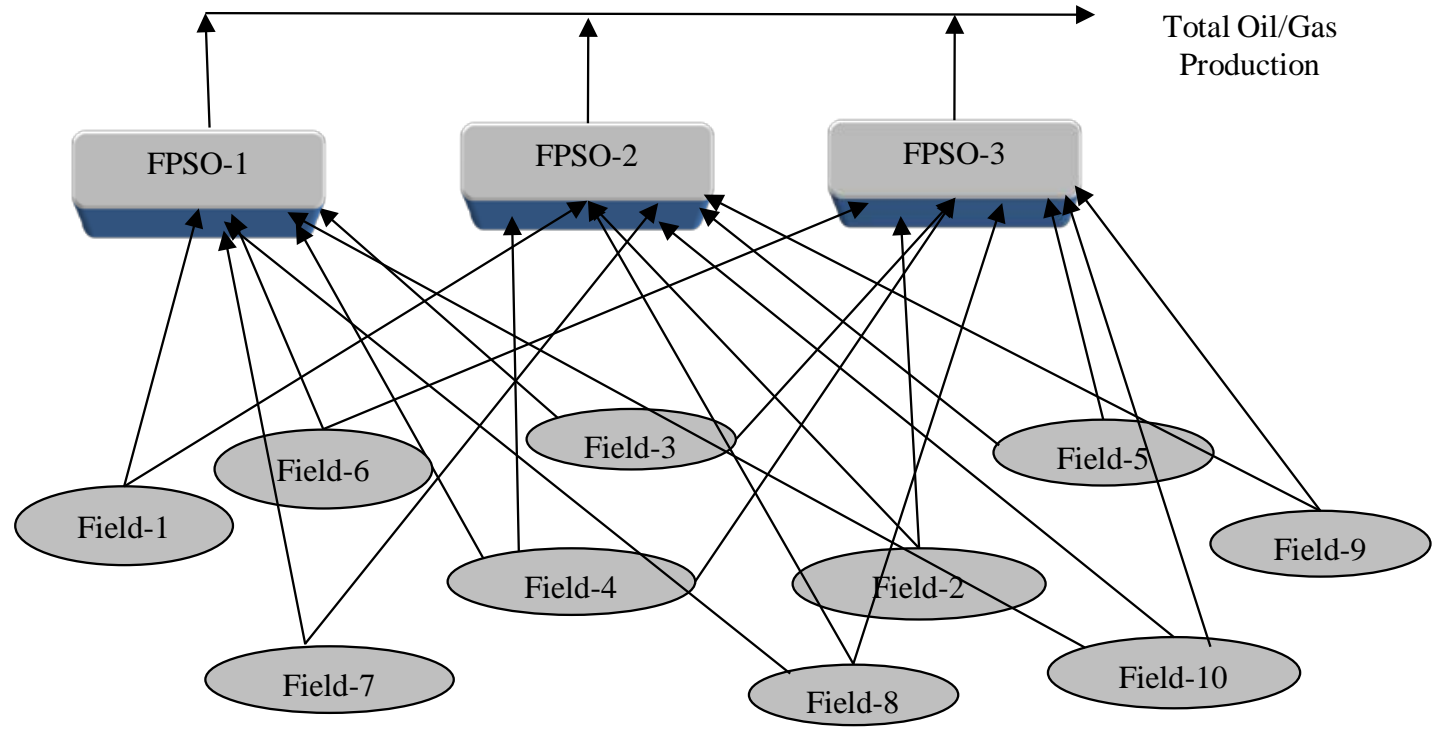

Figure 14: Instance 3 with 10 Fields, 3 FPSO, 20 years 


\subsubsection{PSA without ringfencing provisions for Instance 3}

In this case, we consider a larger instance of the oilfield planning problem with fiscal considerations. There are 10 oil fields (Figure 14) that can be connected to 3 FPSOs with 23 possible connections. There are a total of 84 wells that can be drilled in all of these 10 fields and the planning horizon considered is 20 years. There is a cost recovery ceiling of $50 \%$ and 4 tiers are defined for profit oil split between the contractor and host government that are linked to cumulative oil production. The objective is to maximize the NPV of the contractor's share after paying taxes and corresponding optimal investment/operations decisions.

Table 12. Results for Instance 3 after using various solution strategies

\begin{tabular}{|l|r|r|r|r|r|r|r|}
\hline \multicolumn{1}{|c|}{ Model } & $\begin{array}{c}\text { \# of } \\
\text { constraints }\end{array}$ & $\begin{array}{c}\text { \# of } \\
\text { continuous } \\
\text { variables }\end{array}$ & $\begin{array}{c}\text { \# of } \\
\text { discrete } \\
\text { variables }\end{array}$ & $\begin{array}{c}\text { NPV } \\
\text { (\$Million) }\end{array}$ & $\begin{array}{c}\text { NPV after } \\
\text { fixing } \\
\text { decisions in } \\
\text { Model 3RF } \\
\text { (\$Million) }\end{array}$ & Time (s) & $\begin{array}{c}\text { Optimality } \\
\text { gap } \\
\mathbf{( \% )}\end{array}$ \\
\hline Model 3RF & 17,640 & 11,727 & 963 & $6,440.58$ & - & $>72,000$ & $<22 \%$ \\
\hline Model 3RF-L & 20,240 & 11,727 & 963 & $6,498.45$ & - & 22,500 & $<10 \%$ \\
\hline Model 3RI-A & 17,080 & 11,407 & 883 & $6,355.00$ & $6,452.36$ & 2,035 & $<10 \%$ \\
\hline Model 3RI & 17,080 & 11,407 & 883 & $7,319.60$ & $6,484.12$ & 1,569 & $<10 \%$ \\
\hline
\end{tabular}

Table 12 compares the solution time required for Model 3RF with the proposed reformulation/approximation techniques. We can observe that even Model 3RF without any ringfences becomes expensive to solve for this larger instance as compared to instance 2. Moreover, it takes more than 20hrs to reach within 22\% of optimality for Model 3RF, whereas the relaxed Model 3RI can be solved in less than half an hour within 10\% of optimality. The solution that is obtained after fixing the design decisions in the original formulation is also better than Model 3RF. Model 3RI-A, which is an approximation, also performs similar to the relaxed model and gives an even improved solution than Model 3RF with a 2\% of accuracy. Both models are more than 20 times faster than even the tighter formulation Model 3RF-L involving logic constraints and valid inequalities. Surprisingly, these models perform again better than the model without any fiscal terms, i.e. the simple NPV based model (Model 3R) takes more than 12,000 s to reach within $10 \%$ of optimality gap due to the trade-off that is missing between production and fiscal part.

Notice that the times reported in Table 12 for Model 3RI-A and 3RI are the times to solve Models 3RI-A and 3RI only. We did not include the time required to solve Model 3RF with fixed decisions in all the examples considered since it was negligible as compared to solution 
time of Models 3RI-A, 3RI and 3RF. For instance, it is 2 orders of magnitude smaller than the solution time required for Model 3RI-A (25s vs. 2035s) for this case. It is due to the fact that the critical discrete variables that represent the infrastructure and well drilling are fixed in the model and most of the reaming decisions correspond to the continuous operational decisions.

\subsubsection{PSA with ringfencing provisions for Instance 3}

In this case, we consider three ringfences for the above Instance 3 with 10 fields (see Figure 14) where Table 13 and 14 represent data corresponding to the field sizes, ringfencing provisions and sliding scale profit oil divisions.

Table 13. Field Sizes and Ringfencing Provisions for Instance 3

\begin{tabular}{|c|c|c|c|c|c|c|c|c|c|c|}
\hline Field & F-1 & F-2 & F-3 & F-4 & F-5 & F-6 & F-7 & F-8 & F-9 & F-10 \\
\hline $\begin{array}{c}\text { Field Size } \\
\text { (MMbbl) }\end{array}$ & 60 & 100 & 170 & 230 & 280 & 80 & 200 & 320 & 400 & 500 \\
\hline $\begin{array}{c}\text { Corresponding } \\
\text { Ringfence }\end{array}$ & RF-1 & RF-1 & RF-1 & RF-2 & RF-2 & RF-2 & RF-3 & RF-3 & RF-3 & RF-1 \\
\hline
\end{tabular}

Table 14. Fiscal data for Instance 3 with ringfencing provisions

(i) Sliding scale Contractor’s Profit Oil share (ii) Tax rates and Cost Oil Ceilings

\begin{tabular}{|c|c|c|}
\cline { 2 - 3 } \multicolumn{1}{c|}{} & \multicolumn{2}{c|}{ Ringfences: RF-1, RF-2, RF-3 } \\
\hline & $\begin{array}{c}\text { Cumulative oil } \\
\text { Produced }\end{array}$ & $\begin{array}{c}\text { Contractor's Profit } \\
\text { Oil Share }\end{array}$ \\
\hline Tier-1 & $0-200 \mathrm{MMbbl}$ & $50 \%$ \\
\hline Tier-2 & $200-400 \mathrm{MMbbl}$ & $40 \%$ \\
\hline Tier-3 & $400-600 \mathrm{MMbbl}$ & $30 \%$ \\
\hline Tier-4 & $>600 \mathrm{MMbbl}$ & $20 \%$ \\
\hline
\end{tabular}

\begin{tabular}{|c|c|c|}
\hline Ringfence & $\begin{array}{c}\text { Cost Recovery } \\
\text { Income Tax Rate } \\
\text { (\% of Contractor's } \\
\text { Profit Oil Share) }\end{array}$ & $\begin{array}{c}\text { Ceing } \\
\text { (\% of Gross } \\
\text { Revenues from } \\
\text { the Ring-fence) }\end{array}$ \\
\hline RF-1 & $30 \%$ & $50 \%$ \\
\hline RF-2 & $30 \%$ & $50 \%$ \\
\hline RF-3 & $30 \%$ & $50 \%$ \\
\hline
\end{tabular}

Table 15 compares the computational results of various models for this case of instance 3. It can be observed that including ringfencing provisions for this largest instance makes even both Model 3RF and Model 3RF-L very expensive compared to the previous case without any ringfences. This is due to the additional binary variables that are required in the model for each of the three ringfences separately and resulting weak relaxations.

In contrast, since Models 3RI and 3RI-A do not require binary variables for sliding scales, they perform much better than Model 3RF and its tighter version Model 3RF-L as 
observed in the earlier cases. Model 3RI is a relaxation and yields a tight upper bound, while Model 3RI-A yields an approximate solution within 3\% of accuracy.

Table 15. Results for Instance 3 with Ringfencing provisions

\begin{tabular}{|l|r|r|r|r|r|r|r|}
\hline \multicolumn{1}{|c|}{ Model } & $\begin{array}{c}\text { \# of } \\
\text { constraints }\end{array}$ & $\begin{array}{c}\text { \# of } \\
\text { continuous } \\
\text { variables }\end{array}$ & $\begin{array}{c}\text { \# of } \\
\text { discrete } \\
\text { variables }\end{array}$ & $\begin{array}{c}\text { NPV } \\
\text { (\$Million) }\end{array}$ & $\begin{array}{c}\text { NPV after } \\
\text { fixing } \\
\text { decisions in } \\
\text { Model 3RF } \\
\text { (\$Million) }\end{array}$ & Time (s) & $\begin{array}{c}\text { Optimality } \\
\text { gap } \\
\mathbf{( \% )}\end{array}$ \\
\hline Model 3RF & 33,403 & 22,150 & 1,163 & $6,382.46$ & - & $>72,000$ & $<57 \%$ \\
\hline Model 3RF-L & 41,203 & 22,150 & 1,163 & $6,469.30$ & - & $>72,000$ & $<22 \%$ \\
\hline Model 3RI-A & 31,723 & 21,190 & 923 & $6,273.59$ & $6,442.68$ & 3,383 & $<10 \%$ \\
\hline Model 3RI & 31,723 & 21,190 & 923 & $7,166.70$ & $6,349.99$ & 4,003 & $<10 \%$ \\
\hline
\end{tabular}

Figure 15 represents the optimal installation and connections between fields and FPSO for this problem, where we can observe that each of the installed FPSO (1 and 3) is connected to a total of 5 fields that do not belong to the same ringfence. The optimal cumulative oil production profile for various ringfences is shown in Figure 16, and the sliding scale rules in Table 14(i), results in the different times of higher tier activations for these three ringfences as shown in Table 16. Notice that ringfence 3, which involves larger size fields, enters into higher tier (Tier 4) sooner as compared to the other ringfences. Moreover, in ringfence 2 which has smaller fields, only 3 tiers become active.

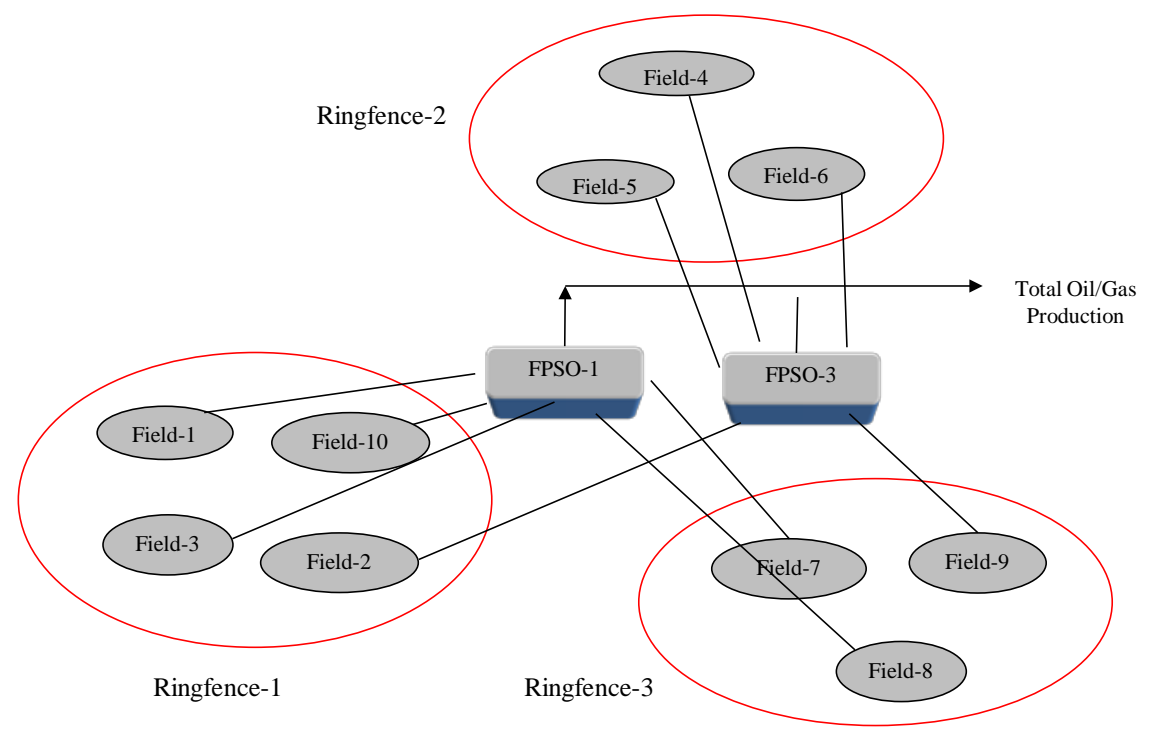

Figure 15: Optimal Solution for Instance 3 with Ringfencing provisions 


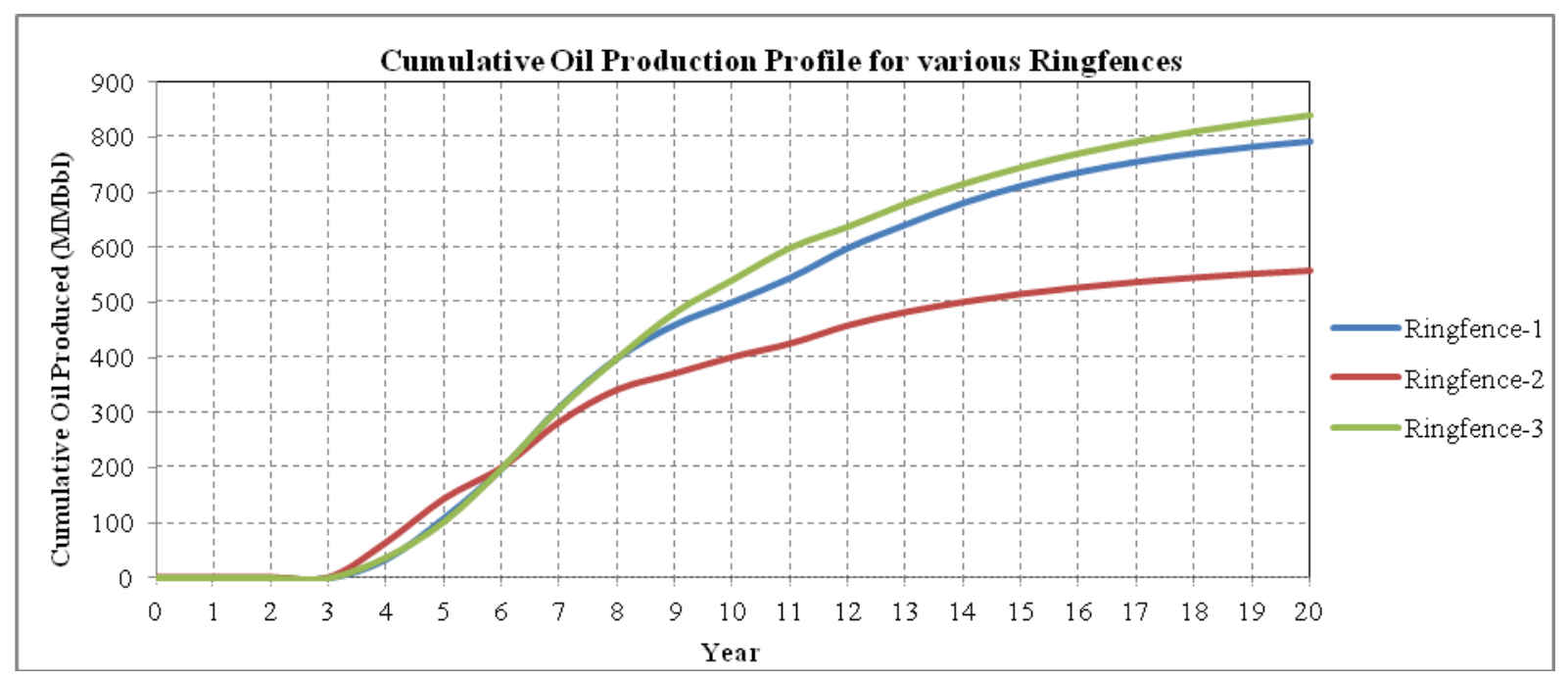

Figure 16: Optimal Cumulative Oil production for Instance 3 with Ringfencing provisions

Table 16. Optimal timings of Tier activations for various Ringfences

\begin{tabular}{|c|c|c|c|c|}
\hline Ringfence & Tier-1 & Tier-2 & Tier-3 & Tier-4 \\
\hline RF-1 & Year 1- Year 6 & Year 7- Year 8 & Year 9- Year 12 & Year 13- Year 20 \\
\hline RF-2 & Year 1- Year 6 & Year 7- Year 10 & Year 11- Year 20 & - \\
\hline RF-3 & Year 1- Year 6 & Year 7- Year 8 & Year 9- Year 11 & Year 12- Year 20 \\
\hline
\end{tabular}

It is important to note that the performance of Models 3RI and 3RI-A is independent of the number of ringfences that are present in the fiscal terms, as it can be seen that the increase in solution time is negligible compared to the previous case without ringfencing provisions. This is due to the fact that increasing ringfences in these models only increases the number of continuous variables and linear constraints, except few binary variables that are required for cost oil recovery calculation. In contrast, the complexity of Models 3RF and 3RF-L that rely on disjunction (30) increases exponentially with an increase in the number of ringfences or tiers. Moreover, it is also interesting to note that even after including one of the extreme cases of the fiscal term (progressive PSA with ringfencing) for a large instance involving 10 fields, the proposed relaxed/approximate models still perform extremely well, and they are in fact even 3-4 times better than the simple NPV based Model 3R without fiscal considerations.

\section{Conclusions}

In this paper, we have addressed the incorporation of fiscal aspects with offshore oil and gas field planning problem. These fiscal considerations are usually either ignored or considered in an 
ad-hoc manner, which may have a very large impact on the planning decisions. In particular, we have proposed a generic model for the multi-field site problems that accounts for the fiscal calculations in the objective functions and constraints explicitly. The model is an extension of the strategic/tactical planning model presented in Gupta and Grossmann ${ }^{17}$ with progressive PSAs involving ringfencing provisions. Few simpler cases of the fiscal contracts have also been derived from the proposed general model as an illustration. The model yields investment and operating decisions that are not only optimal in the sense of NPV after taxes for the project at hand, but also provides a more appropriate basis to compare a portfolio of different projects involving different fiscal contracts and other details. However, as the computational expense can be a serious issue with the incorporation of fiscal terms for some particular contract, we have also proposed some reformulation/approximation techniques and solution strategies that allow to overcome this issue. Numerical results in realistic examples show that these models and solution strategies are quite efficient, and reduce the solution time orders of magnitude than using the MILP for the disjunctive formulation. We hope that this paper has shown that explicit consideration of the fiscal rules is important for oilfield infrastructure planning, and that the models/methods described here can serve as the basis for further extensions and improvements in the computational effort.

\section{Acknowledgments}

The author would like to acknowledge ExxonMobil Upstream Research Company for the financial support of this work.

\section{Supporting Information Available}

This information is available free of charge via the Internet at http://pubs.acs.org/.

\section{References}

(1) BP Statistical Review of World Energy, 2011.

(2) Lee A. S.; Aronofsky J. S. A linear programming model for scheduling crude oil production. J. Petrol Tech. 1958, 10, 51-54.

(3) Aronofsky J. S.; Williams A. C. The use of linear programming and mathematical models in underground oil production. Manage. Sci. 1962, 8,394-407. 
(4) Frair, L. C. Economic Optimization of Offshore Oilfield Development. PhD Dissertation, University of Oklahoma, Tulsa, OK, 1973.

(5) Bohannon J. A linear programming model for optimum development of multi-reservoir pipeline systems. J. Petrol Tech. 1970, 22, 1429-1436.

(6) Sullivan J. A computer model for planning the development of an offshore gas field. $J$. Petrol Tech. 1982, 34, 1555-1564.

(7) Haugland, D.; Hallefjord, A.; Asheim, H. Models for petroleum field exploitation. Eur. J. Oper. Res. 1988, 37 (1), 58-72.

(8) Behrenbruch, P. Offshore oilfield development planning. J. Pet. Technol. 1993, 45 (8), 735-743.

(9) Iyer, R. R.; Grossmann, I. E.; Vasantharajan, S.; Cullick, A. S. Optimal planning and scheduling offshore oilfield infrastructure investment and operations. Ind. Eng. Chem. Res. 1998, 37, 1380-1397.

(10) van den Heever, S. A.; Grossmann, I. E. An iterative aggregation/disaggregation approach for the solution of a mixed integer nonlinear oilfield infrastructure planning model. Ind. Eng. Chem. Res. 2000, 39, 1955-1971.

(11) Kosmidis, V.; Perkins, J.; Pistikopoulos, E. A mixed integer optimization strategy for integrated gas/oil production. In: European Symposium on Computer Aided Process Engineering. Vol. 12, 2002.

(12) Barnes, R.; Linke, P.; Kokossis, A. Optimization of oil-field development production capacity. European symposium on computer aided process engineering, Vol. 12 (p. 631), 2002.

(13) Ortiz-Gomez, A.; Rico-Ramirez, V.; Hernandez-Castro, S. Mixed-integer multiperiod model for the planning of oil-field production. Comput. Chem. Eng. 2002, 26(4-5), 703.

(14) Tsarbopoulou, C. Optimization of oil facilities and oil production. M.Sc. Dissertation, University College London, London, U.K., 2000.

(15) Carvalho, M.; Pinto, J. M. A bilevel decomposition technique for the optimal planning of offshore platforms. Brazilian J. Chem. Eng. 2006, 23, 67-82.

(16) Carvalho, M.; Pinto, J. M. An MILP model and solution technique for the planning of infrastructure in offshore oilfields. J. Pet. Sci. Eng. 2006, 51, 97-110.

(17) Gupta, V.; Grossmann, I. E. An Efficient Multiperiod MINLP Model for Optimal Planning of Offshore Oil and Gas Field Infrastructure. Ind. Eng. Chem. Res., 2012, 51 (19), 6823-6840.

(18) Haugen, K. K. A stochastic dynamic programming model for scheduling of offshore petroleum fields with resource uncertainty. Eur. J. Oper. Res., 1996, 88 (1), 88-100.

(19) Jonsbraten, T. W. Oil-field optimization under price uncertainty. J. Oper. Res. Soci. 1998, 49, 811.

(20) Jonsbraten, T. W.; Wets, R. J. B.; Woodruff, D. L. A class of stochastic programs with decision dependent random elements. Ann. Oper. Res. 1998, 82, 83-106.

(21) Aseeri, A.; Gorman, P.; Bagajewicz, M. J. Financial risk management in offshore oil infrastructure planning and scheduling. Ind. Eng. Chem. Res. 2004, 43, 3063-3072. 
(22) Lund, M. W. Valuing Flexibility in Offshore Petroleum Projects. Ann. Oper. Res. 2000, 99 (1-4), 325-349.

(23) Cullick, A. S.; Heath D.; Narayanan K.; April J.; Kelly J. Optimizing Multiple-Field Scheduling and Production Strategy with Reduced Risk. Presented at the SPE Annual Technical Conference and Exhibition, Denver, CO, Oct 5-8, 2003; Paper SPE 84239.

(24) Goel, V.; Grossmann, I. E. A stochastic programming approach to planning of offshore gas field developments under uncertainty in reserves. Comput. Chem. Eng. 2004, 28 (8), 14091429.

(25) Goel, V.; Grossmann, I. E. A Class of Stochastic Programs with Decision Dependent Uncertainty. Math. Program. (Ser. B) 2006, 108, 355-394.

(26) Goel, V.; Grossmann, I. E.; El-Bakry, A. S.; Mulkay, E. L. A novel branch and bound algorithm for optimal development of gas fields under uncertainty in reserves. Comput. Chem. Eng. 2006, 30, 1076-1092.

(27) Tarhan, B.; Grossmann, I.E.; Goel, V. Stochastic programming approach for the planning of offshore oil or gas field infrastructure under decision- dependent uncertainty. Ind. Eng. Chem. Res. 2009, 48(6), 3078-3097.

(28) Tarhan, B.; Grossmann, I.E.; Goel, V. Computational strategies for non-convex multistage MINLP models with decision-dependent uncertainty and gradual uncertainty resolution. Ann. Oper. Res., DOI: 10.1007/s10479-011-0855-x.

(29) Gupta, V.; Grossmann, I. E. Solution strategies for multistage stochastic programming with endogenous uncertainties. Comput. Chem. Eng. 2011, 35, 2235-2247.

(30) Bagajewicz, M. J. On the use of net present value in investment capacity planning models. Ind. Eng. Chem. Res., 2008, 47, 9413-9416.

(31) Lainez, J. M.; Puigjaner, L.; Reklaitis, G. V. Financial and financial engineering considerations in supply chain and product development pipeline management. Comput. Chem. Eng., 2009, 33, 1999-2011.

(32) van den Heever, S. A.; Grossmann, I. E.; Vasantharajan, S.; Edwards, K. Integrating complex economic objectives with the design and planning of offshore oilfield infrastructures. Comput. Chem. Eng. 2000, 24, 1049-1055.

(33) van den Heever, S. A.; Grossmann, I. E. A Lagrangean Decomposition Heuristic for the Design and Planning of Offshore Hydrocarbon Field Infrastructures with Complex Economic Objectives. Ind. Eng. Chem. Res. 2001, 40, 2857-2875.

(34) Lin, X.; Floudas, C. A. A Novel Continuous-Time Modeling and Optimization Framework for Well Platform Planning Problems. Optim. Eng. 2003, 4 (1-2), 65-95.

(35) Blake, A. J.; Roberts, M. C. Comparing petroleum fiscal regimes under oil price uncertainty. Resources Policy, 2006, 31(2), 95-105.

(36) Kaiser, M.J.; Pulsipher;, A.G. Fiscal System Analysis: Concessionary and Contractual Systems Used in Offshore Petroleum Arrangements. US Department of the Interior Mineral Management Services MMS 2004-016, 1-78.

(37) Gupta, V.; Grossmann, I. E. Offshore Oilfield Development Planning under Uncertainty and Fiscal Considerations. Optimization and Analytics in the Oil and Gas Industry, Part I; Springer Edition, 2011, Submitted for publication. 
(38) Babusiaux, D.; Favennec, J. P.; Bauquis, P. R.; Bret-Rouzaut, N.; Guirauden, D. Oil and Gas Exploration and Production: Reserves, costs, contracts; Technip edition, 2007.

(39) Johnston, D. Petroleum Fiscal Systems and Production Sharing Contracts; PennWell Publishing Co.: Tulsa, Oklahoma, 1994.

(40) Sunley, E. M.; Baunsgaard T.; Simard D. Revenue from the Oil and Gas Sector: Issues and Country Experience. IMF Conference Paper 2002.

(41) Tordo, S. Fiscal Systems of Hydrocarbons: Design Issues.Working Paper 123/07, World Bank, Washington, D.C, 2007.

(42) World Bank. Contracts for Petroleum Development - Part 1-3. Petroleum Sector Briefing Note No. 7, 2007.

(43) Glover, F. Improved Linear Integer Programming Formulations of Nonlinear Integer Problems. Manage. Sci. 1975, 22, 455.

(44) Raman, R.; Grossmann, I. E. Modeling and Computational Techniques for Logic-Based Integer Programming. Comput. Chem. Eng., 1994, 18, 563-578

(45) Grossmann, I. E. Review of nonlinear mixed-integer and disjunctive programming techniques for process systems engineering. Optim. Eng. 2002, 3 (3), 227-252.

(46) Raman, R.; Grossmann, I. E. Relation between MILP Modeling and Logical Inference for Chemical Process Synthesis. Comput. Chem. Eng. 1991, 15 (2), 73-84.

\section{Nomenclature}

\section{Indices}

$t, \tau$

$f$

fpso

$r f$

i

\section{Binary Variables}

$b_{f p s o, t}^{F P S O}$

$b_{f, f p s o, t}$

$b_{f, f p s o}^{o n}$

$Z_{r f, i, t}$

$b_{r f, t}^{c o}$

\section{Integer Variables}

$I_{f, t}^{\text {well }}$ time periods, $t, \tau \in T$

field

FPSO facility

ringfence

tier

whether or not FPSO facility fpso is installed at the beginning of time period $t$

whether or not a connection between field $f$ and FPSO facility fpso is installed at the beginning of time period $t$

whether or not a connection between field $f$ and FPSO facility fpso is installed

whether or not tier $i$ is active in time period $t$ for ringfence $r f$

whether or not cost ceiling is active in time period $t$ for ringfence $r f$

Number of wells drilled in field $f$ at the beginning of time period $t$ 


\section{Continuous Variables}

NPV

TotalConSh ${ }_{t}^{\text {tot }}$

$C A P_{t}^{t o t}$

$O P E R_{t}^{\text {tot }}$

TotalConSh $_{r f, t}$

$\operatorname{COST}_{r f, t}$

$C A P_{r f, t}$

$C A P 1_{r f, t}$

$C A P 2_{r f, t}$

$O P E R_{r f, t}$

FPSOC $_{f p s o, t}$

DFPSOC $_{r f, f p s o, t}$

DFPSOC $_{f, f p s o, t}^{\text {field }}$

$R E V_{r f, t}$

$Z D_{f^{\prime}, f, f p s o, t}^{\text {field }}$

$Z D 1_{f^{\prime}, f, f p s o, t}^{\text {field }}$

$Z D_{f, f p s o, t}$

$Z D 1_{f, f p s o, t}$

$x_{r f, t}^{t o t}$

$w_{r f, t}^{\text {tot }}$

$g_{r f, t}^{\text {tot }}$

$X C_{r f, t}$

$X_{f, t}$

$w_{f, t}$

$g_{f, t}$

$x C_{f, t}^{\text {field }}$

wor $_{f, f p s o, t}$

gor $_{f, f p s o, t}$

$W C_{f, f p s o, t}$ net present value

total contractor share in time period $t$

total capital costs in time period $t$

total operating costs in time period $t$

contractor share in time period $t$ for ringfence $r f$

total capital and operating costs in time period $t$ for ringfence $r f$

capital costs in time period $t$ for ringfence $r f$

field specific capital costs in time period $t$ for ringfence $r f$

FPSO specific capital costs in time period $t$ for ringfence $r f$

operating costs in time period $t$ for ringfence $r f$

total cost of FPSO facility fpso in time period $t$

disaggregated cost of FPSO facility fpso in time period $t$ for ringfence $r f$

disaggregated cost of FPSO facility fpso in time period $t$ for field $f$

total revenues in time period $t$ for ringfence $r f$

auxiliary variable for $b_{f^{\prime}, \text { fpso }}^{\text {on }} \cdot D F P S O C_{f, f p s o, t}^{\text {field }}$

auxiliary variable for $b_{f ', f p s o}^{\text {on }} \cdot$ DFPSOC $_{f, f p s o, t}^{\text {field }}$

auxiliary variable for $b_{f, f p s o}^{o n} \cdot F P S O C_{f p s o, t}$

auxiliary variable for $b_{f, f p s o}^{o n} \cdot F P S O C_{f p s o, t}$

total oil production rate from ringfence $r f$ in time period $t$

total water production rate from ringfence $r f$ in time period $t$

total gas production rate from ringfence $r f$ in time period $t$

cumulative oil produced from ringfence $r f$ by the end of time period $t$

oil production rate from field $f$ in time period $t$

water production rate from field $f$ in time period $t$

gas production rate from field $f$ in time period $t$

cumulative oil produced from field $f$ by the end of time period $t$

water-to-oil ratio for field-FPSO connection in time period $t$

gas-to-oil ratio for field-FPSO connection in time period $t$

cumulative water produced from field $f$ to FPSO facility fpso by the end of time period $t$ 


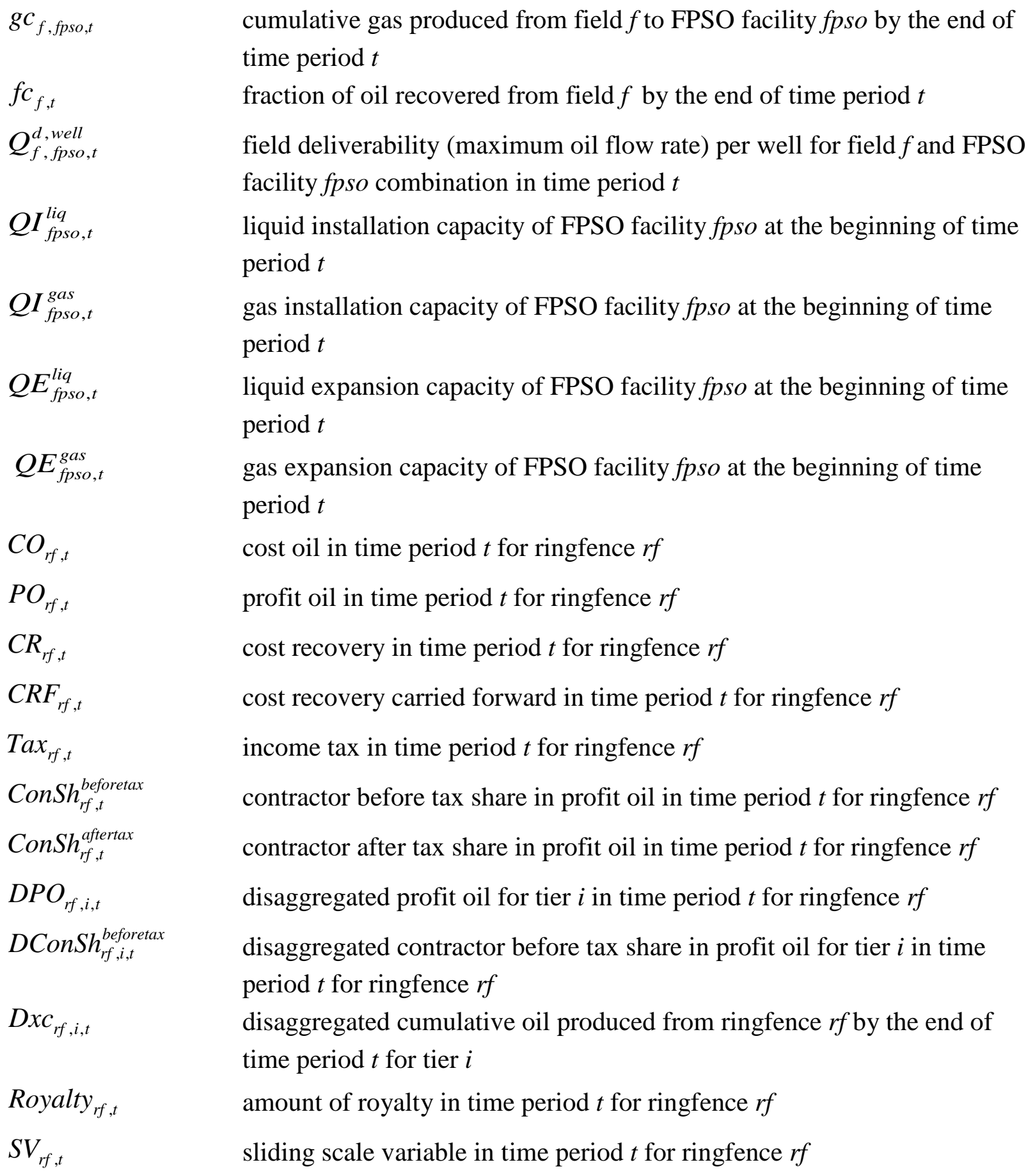

cumulative gas produced from field $f$ to FPSO facility fpso by the end of time period $t$ fraction of oil recovered from field $f$ by the end of time period $t$ field deliverability (maximum oil flow rate) per well for field $f$ and FPSO facility fpso combination in time period $t$

liquid installation capacity of FPSO facility fpso at the beginning of time period $t$

gas installation capacity of FPSO facility fpso at the beginning of time period $t$

liquid expansion capacity of FPSO facility fpso at the beginning of time period $t$

gas expansion capacity of FPSO facility fpso at the beginning of time period $t$

cost oil in time period $t$ for ringfence $r f$

profit oil in time period $t$ for ringfence $r f$

cost recovery in time period $t$ for ringfence $r f$

cost recovery carried forward in time period $t$ for ringfence $r f$

income tax in time period $t$ for ringfence $r f$

contractor before tax share in profit oil in time period $t$ for ringfence $r f$

contractor after tax share in profit oil in time period $t$ for ringfence $r f$

disaggregated profit oil for tier $i$ in time period $t$ for ringfence $r f$

disaggregated contractor before tax share in profit oil for tier $i$ in time period $t$ for ringfence $r f$

disaggregated cumulative oil produced from ringfence $r f$ by the end of time period $t$ for tier $i$

amount of royalty in time period $t$ for ringfence $r f$

sliding scale variable in time period $t$ for ringfence $r f$

\section{Parameters}

$F C_{f, f p s o, t}$

fixed capital cost for installing FPSO facility fpso at the beginning of time period $\mathrm{t}$

fixed cost for installing the connection between field $f$ and FPSO facility fpso at the beginning of time period $\mathrm{t}$ 


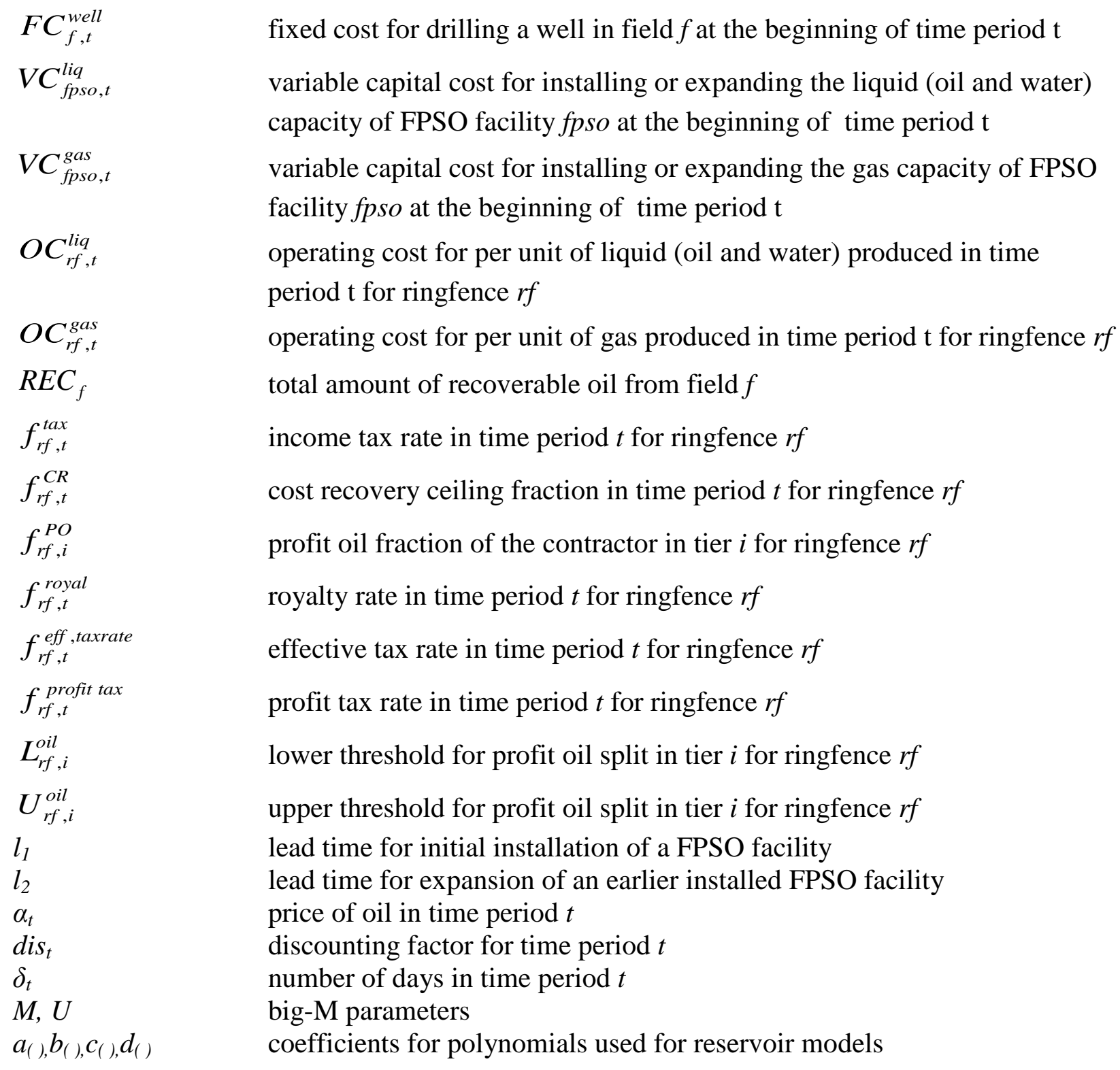

$F C_{f, t}^{\text {well }}$

$V C_{f p s o, t}^{\text {liq }}$

$V C_{f p s o, t}^{g a s}$

$O C_{r f, t}^{l i q}$

$O C_{r f, t}^{g a s}$

$R E C_{f}$

$f_{r f, t}^{\operatorname{tax}}$

$f_{r f, t}^{C R}$

$f_{r f, i}^{P O}$

$f_{r f, t}^{\text {royal }}$

$f_{r f, t}^{\text {eff,taxrate }}$

$f_{r f, t}^{p r o f i t ~ t a x}$

$L_{r f, i}^{o i l}$

$U_{r f, i}^{\text {oil }}$

$l_{1}$

$l_{2}$

$\alpha_{t}$

$\operatorname{dis}_{t}$

$\delta_{t}$

$M, U$

$a_{(),} b_{(), C_{(}, d_{()}}$

fixed cost for drilling a well in field $f$ at the beginning of time period $\mathrm{t}$ variable capital cost for installing or expanding the liquid (oil and water) capacity of FPSO facility fpso at the beginning of time period $t$ variable capital cost for installing or expanding the gas capacity of FPSO facility fpso at the beginning of time period $\mathrm{t}$

operating cost for per unit of liquid (oil and water) produced in time period t for ringfence $r f$

operating cost for per unit of gas produced in time period t for ringfence $r f$ total amount of recoverable oil from field $f$

income tax rate in time period $t$ for ringfence $r f$

cost recovery ceiling fraction in time period $t$ for ringfence $r f$

profit oil fraction of the contractor in tier $i$ for ringfence $r f$

royalty rate in time period $t$ for ringfence $r f$

effective tax rate in time period $t$ for ringfence $r f$

profit tax rate in time period $t$ for ringfence $r f$

lower threshold for profit oil split in tier $i$ for ringfence $r f$

upper threshold for profit oil split in tier $i$ for ringfence $r f$

lead time for initial installation of a FPSO facility

lead time for expansion of an earlier installed FPSO facility

price of oil in time period $t$

discounting factor for time period $t$

number of days in time period $t$

big-M parameters

coefficients for polynomials used for reservoir models

\section{Appendix A}

Proposition 1: If the sliding scale variable for profit oil share of the contractor is cumulative oil produced, the following inequalities are satisfied at the optimal solution of Model 3RF:

$$
\begin{array}{r}
\sum_{\tau \leq t}\left(\text { Contsh }_{r f, \tau}^{\text {beforetax }} / \alpha_{\tau}\right) \leq \sum_{i^{\prime}=1}^{i^{\prime} \leq i}\left(f_{r f, i^{\prime}}^{P O}-f_{r f, i^{\prime}-1}^{P O}\right) \cdot\left(x C_{r f, t}-L_{r f, i^{\prime}}\right)-f_{r f, i^{\text {end }}}^{P O} \cdot \sum_{\tau \leq t}\left(C O_{r f, \tau} / \alpha_{\tau}\right) \\
\forall r f, i, t
\end{array}
$$

Proof: The proof follows from bounding the cumulative contractor's share in each time period for every ringfence. We know that the revenue generated from a ringfence $\mathrm{rf}$ in time period $\mathrm{t}$, 
equation (A2), is the total oil produced from this ringfence in that time period times the price of oil $\left(\alpha_{t}\right)$. From Figure 2, we can observe that the total profit oil for a ringfence in time period $t$ is the difference between revenue and cost oil for that ringfence, where we consider no royalty provisions that yields equation (A3).

$$
\begin{array}{ll}
R E V_{r f, t}=\alpha_{t} x_{r f, t}^{\text {tot }} & \forall r f, t \\
P O_{r f, t}=R E V_{r f, t}-C O_{r f, t} & \forall r f, t
\end{array}
$$

If tier $i(t)$ is active in time period $t$ for ringfence rf, then the contractor share in the profit oil for that ringfence can be calculated in eq. (A4) as the corresponding profit oil times the tier fraction which is active in the current period $t, f_{r f, i(t)}^{P O}$. Equation (A4) can be re-written as eq. (A5) using eq. (A3), and dividing the both sides of the resulting equation by price of oil to represent the contractor's share in terms of oil volume instead of price.

ContSh $_{r f, t}^{\text {beforetax }}=f_{r f, i(t)}^{P O} \cdot P O_{r f, t}$, where tier $i(t)$ is active for rf in time period $t \quad \forall r f, t$ (A4) ContSh $r_{r f, t}^{\text {befretax }} / \alpha_{t}=f_{r f, i(t)}^{P O} \cdot\left(R E V_{r f, t}^{\text {tot }}-C O_{r f, t}\right) / \alpha_{t}$, where tier $i(t)$ is active for rf in time $\mathrm{t}$

$$
\forall r f, t \text { (A5) }
$$

The cumulative contractor's share by the end of time period t can be obtained in equation (A6) by summing (A5) from period 1 to current period t, which can further be re-written as equation (A7) using revenue definition form equation (A2).

$$
\begin{aligned}
& \sum_{\tau=1}^{t} \operatorname{ContSh}_{r f, \tau}^{\text {beforetax }} / \alpha_{\tau}=\sum_{\tau=1}^{t} f_{r f, i(\tau)}^{P O} \cdot\left(R E V_{r f, \tau}^{\text {tot }}-C O_{r f, \tau}\right) / \alpha_{\tau} \\
& \sum_{\tau=1}^{t} \operatorname{ContSh}_{r f, \tau}^{\text {beforetax }} / \alpha_{\tau}=\sum_{\tau=1}^{t} f_{r f, i(\tau)}^{P O} \cdot x_{r f, \tau}^{\text {tot }}-\sum_{\tau=1}^{t} f_{r f, i(\tau)}^{P O} \cdot C O_{r f, \tau} / \alpha_{\tau}
\end{aligned}
$$

The first term in RHS of equation (A7) can be written as in equation (A8) for an active tier $i(t)$ for ringfence if in time period $t$, where, $t_{1}, t_{2}$ and so on are the time periods until previous tiers 1, 2, 3, etc. were active, respectively, for the corresponding ringfence. Equation (A9) represents (A8) in terms of cumulative oil produced in each tier until tier i(t).

$$
\sum_{\tau=1}^{t} f_{r f, i(\tau)}^{P O} \cdot x_{r f, \tau}^{t o t}=f_{r f, 1}^{P O} \sum_{\tau=1}^{t_{1}} x_{r f, \tau}^{t o t}+f_{r f, 2}^{P O} \sum_{\tau=t_{1}+1}^{t_{2}} x_{r f, \tau}^{t o t}+\ldots+f_{r f, i-1}^{P O} \sum_{\tau=t_{i-2}+1}^{t_{i-1}} x_{r f, \tau}^{t o t}+f_{r f, i(t)}^{P O} \sum_{\tau=t_{i-1}+1}^{t} x_{r f, \tau}^{t o t} \quad \forall r f, t
$$




$$
\sum_{\tau=1}^{t} f_{r f, i(\tau)}^{P O} \cdot x_{r f, \tau}^{\mathrm{tot}}=f_{r f, 1}^{P O} X C_{r f, t_{1}}+f_{r f, 2}^{P O} X C_{r f, t_{2}-t_{1}}+\ldots+f_{r f, i-1}^{P O} X C_{r f, t_{i-1}-t_{i-2}}+f_{r f, i(t)}^{P O} X C_{r f, t-t_{i-1}} \quad \forall r f, t \text { (A9) }
$$

The maximum amount of cumulative oil produced during each tier that lies before tier i(t) as in (A10), will be the difference between the lower thresholds of the corresponding consecutive tiers as represented in inequality (A11) and can be seen in Figure 5.

$$
\begin{aligned}
& f_{r f, 1}^{P O}>f_{r f, 2}^{P O}>\ldots \ldots . .>f_{r f, i-1}^{P O}>f_{r f, 1}^{P O} \geq 0 \\
& \sum_{\tau=1}^{t} f_{r f, i(\tau)}^{P O} \cdot x_{r f, \tau}^{t o t} \leq f_{r f, 1}^{P O}\left(L_{r f, 2}-L_{r f, 1}\right)+f_{r f, 2}^{P O}\left(L_{r f, 3}-L_{r f, 2}\right)+\ldots+f_{r f, i-1}^{P O}\left(L_{r f, i}-L_{r f, i-1}\right)+f_{r f, i(t)}^{P O}\left(x c_{r f, t}^{t o t}-L_{r f, i}\right) \\
& \forall r f, t
\end{aligned}
$$

Inequality (A11) can further be rewritten as (A12), which by reformulating the last term as in (A13) and rearranging the corresponding terms for each tier gives inequality (A14).

$$
\begin{aligned}
& \sum_{\tau=1}^{t} f_{r f, i(\tau)}^{P O} \cdot x_{r f, \tau}^{t o t} \leq-L_{r f, 1} f_{r f, 1}^{P O}-L_{r f, 2}\left(f_{r f, 2}^{P O}-f_{r f, 1}^{P O}\right)-\ldots . .-L_{r f, i}\left(f_{r f, i}^{P O}-f_{r f, i-1}^{P O}\right)+f_{r f, i(t)}^{P O} X c_{r f, t}^{t o t} \quad \forall r f, t \\
& \sum_{\tau=1}^{t} f_{r f, i(\tau)}^{P O} \cdot x_{r f, \tau}^{t o t} \leq-L_{r f, 1} f_{r f, 1}^{P O}-L_{r f, 2}\left(f_{r f, 2}^{P O}-f_{r f, 1}^{P O}\right)-\ldots . .-L_{r f, i}\left(f_{r f, i}^{P O}-f_{r f, i-1}^{P O}\right) \\
& +x C_{r f, t}^{\text {tot }}\left\{\left(f_{r f, i(t)}^{P O}-f_{r f, i-1}^{P O}\right)+\left(f_{r f, i-1}^{P O}-f_{r f, i-2}^{P O}\right)+\ldots . .\left(f_{r f, 2}^{P O}-f_{r f, 1}^{P O}\right)+f_{r f, 1}^{P O}\right\} \forall r f, t \\
& \sum_{\tau=1}^{t} f_{r f, i(t)}^{P O} \cdot x_{r f, \tau}^{t o t} \leq \sum_{i^{\prime}=1}^{i^{\prime} \leq i(t)}\left(f_{r f, i^{\prime}}^{P O}-f_{r f, i^{\prime}-1}^{P O}\right) \cdot\left(x C_{r f, t}-L_{r f, i^{\prime}}\right)=R H S(i(t))
\end{aligned}
$$

As it is unknown a priori which tier i gets active at what time, we need to write constraint (A14) for each tier $\mathrm{i}$ in each time t. For those tiers that are not active in current period t, i.e. $i \neq i(t)$, (A14) must be relaxed to be a valid inequality. Therefore, for $i^{b}<i(t)$, RHS of inequality (A14) becomes:

$$
R H S\left(i^{b}\right)=\sum_{i^{\prime}=1}^{i^{\prime} \leq i^{b}}\left(f_{r f, i^{\prime}}^{P O}-f_{r f, i^{\prime}-1}^{P O}\right) \cdot\left(x C_{r f, t}-L_{r f, i^{\prime}}\right) \quad \forall i^{b}<i(t), r f, t
$$

Furthermore, on subtracting RHS of eq. (A14) and (A15), it gives (A16), and therefore, we obtain (A17):

$$
\begin{array}{r}
R H S(i(t))-R H S\left(i^{b}\right)=\sum_{i^{\prime}=1}^{i^{\prime} \leq i(t)}\left(f_{r f, i^{\prime}}^{P O}-f_{r f, i^{\prime}-1}^{P O}\right) \cdot\left(x C_{r f, t}-L_{r f, i^{\prime}}\right)-\sum_{i^{\prime}=1}^{i^{\prime} \leq i^{b}}\left(f_{r f, i^{\prime}}^{P O}-f_{r f, i^{\prime}-1}^{P O}\right) \cdot\left(x C_{r f, t}-L_{r f, i^{\prime}}\right) \\
\forall i^{b}<i(t), r f, t \quad(A 16)
\end{array}
$$




$$
\begin{array}{ll}
R H S(i(t))-R H S\left(i^{b}\right)=\sum_{i^{\prime}=i^{b}+1}^{i^{\prime} \leq i(t)}\left(f_{r f, i^{\prime}}^{P O}-f_{r f, i^{\prime}-1}^{P O}\right) \cdot\left(x c_{r f, t}-L_{r f, i^{\prime}}\right) & \forall i^{b}<i(t), r f, t \\
\text { as } \quad\left(f_{r f, i^{\prime}}^{P O}-f_{r f, i^{\prime}-1}^{P O} \leq 0\right) \wedge\left(x c_{r f, t}-L_{r f, i^{\prime}} \geq 0\right) & \forall i^{\prime} \leq i(t), r f
\end{array}
$$

Therefore, (A17) yields (A18) and hence we get (A19) which say that the first term in equation (A7) will be relaxed for all $i^{b}<i(t)$ compared to an active tier i(t).

$$
\begin{array}{ll}
R H S(i(t))-R H S\left(i^{b}\right) \leq 0 & \forall i^{b}<i(t), r f, t \\
R H S(i(t)) \leq R H S\left(i^{b}\right) & \forall i^{b}<i(t), r f, t
\end{array}
$$

For those tiers that lies after active tier i(t), i.e. $i^{a}>i(t)$, then RHS of inequality (A14) becomes:

$$
R H S\left(i^{a}\right)=\sum_{i^{\prime}=1}^{i^{\prime} \leq i^{a}}\left(f_{r f, i^{\prime}}^{P O}-f_{r f, i^{\prime}-1}^{P O}\right) \cdot\left(x C_{r f, t}-L_{r f, i^{\prime}}\right) \quad \forall i^{a}>i(t), r f, t
$$

On subtracting RHS of eq. (A14) and (A20), it gives (A21), which reduces to (A22):

$$
\begin{array}{ll}
R H S(i(t))-R H S\left(i^{a}\right)=\sum_{i^{\prime}=1}^{i^{\prime} \leq i(t)}\left(f_{r f, i^{\prime}}^{P O}-f_{r f, i^{\prime}-1}^{P O}\right) \cdot\left(x c_{r f, t}-L_{r f, i^{\prime}}\right)-\sum_{i^{\prime}=1}^{i^{\prime} \leq i^{a}}\left(f_{r f, i^{\prime}}^{P O}-f_{r f, i^{\prime}-1}^{P O}\right) \cdot\left(x c_{r f, t}-L_{r f, i^{\prime}}\right) \\
\forall i^{a}>i(t), r f, t \quad(A 21) \\
R H S(i(t))-R H S\left(i^{a}\right)=-\sum_{i^{\prime}=i(t)+1}^{i^{\prime} \leq i^{a}}\left(f_{r f, i^{\prime}}^{P O}-f_{r f, i^{\prime}-1}^{P O}\right) \cdot\left(x c_{r f, t}-L_{r f, i^{\prime}}\right) & \forall i^{a}>i(t), r f, t \\
\text { as } \quad\left(f_{r f, i^{\prime}}^{P O}-f_{r f, i^{\prime}-1}^{P O} \leq 0\right) \wedge\left(x c_{r f, t}-L_{r f, i^{\prime}} \leq 0\right) & \forall i^{\prime} \geq i(t), r f
\end{array}
$$

Therefore, (A22) yields (A23) and hence we get (A24) which say that the first term in equation (A7) will be relaxed for $i^{a}>i(t)$ as compared to $\mathrm{i}(\mathrm{t})$.

$$
\begin{array}{ll}
R H S(i(t))-\operatorname{RHS}\left(i^{a}\right) \leq 0 & \forall i^{a}>i(t), r f, t \\
R H S(i(t)) \leq \operatorname{RHS}\left(i^{a}\right) & \forall i^{a}>i(t), r f, t
\end{array}
$$

Therefore, for any tier i which may be an active tier in time t, the first term in eq. (A7) can be represented as inequality (A14).

Equation (A25) represents the second term of RHS for equation (A7) in disaggregated form for each tier as explained above for total oil produced, i.e. equation (A8). However, here 
we do not have any predefined threshold for the cost oil in each tier in contrast to the cumulative oil produced, we need to represent this term in the relaxed form to be valid for all tiers. Given that profit oil fraction decreases as we move to higher tier, eq. (A10) and $C O_{r f, t} \geq 0, \alpha_{t}>0$, we can replace the profit oil fractions for the previous tiers $i^{b}<i(t)$ with the profit oil fraction of the current tier $\mathrm{i}(\mathrm{t})$ that ensures a lower bound on the LHS of equation (A25). Using this relaxation idea we obtain equation (A26) which on further aggregation yields equation (A27) and (A28).

$$
\begin{aligned}
& \sum_{\tau=1}^{t} f_{r f, i(t)}^{P O} \cdot C O_{r f, \tau} / \alpha_{\tau}=f_{r f, 1}^{P O} \sum_{\tau=1}^{t_{1}} C O_{r f, \tau} / \alpha_{\tau}+f_{r f, 2}^{P O} \sum_{\tau=t_{1}}^{t_{2}} C O_{r f, \tau} / \alpha_{\tau}+\ldots+f_{r f, i-1}^{P O} \sum_{\tau=t_{i-2}}^{t_{i-1}} C O_{r f, \tau} / \alpha_{\tau}+f_{r f, i}^{P O} \sum_{\tau=t_{i-1}}^{t} C O_{r f, \tau} / \alpha_{\tau} \\
& \forall r f, t \\
& \sum_{\tau=1}^{t} f_{r f, i(t)}^{P O} \cdot C O_{r f, \tau} / \alpha_{\tau} \geq f_{r f, i(t)}^{P O} \sum_{\tau=1}^{t_{1}} C O_{r f, \tau} / \alpha_{\tau}+f_{r f, i(t)}^{P O} \sum_{\tau=t_{1}}^{t_{2}} C O_{r f, \tau} / \alpha_{\tau}+\ldots+f_{r f, i(t)}^{P O} \sum_{\tau=t_{i-2}}^{t_{i-1}} C O_{r f, \tau} / \alpha_{\tau}+f_{r f, i(t)}^{P O} \sum_{\tau=t_{i-1}}^{t} C O_{r f, \tau} / \alpha_{\tau} \\
& \forall r f, t \\
& \sum_{\tau=1}^{t} f_{r f, i(t)}^{P O} \cdot C O_{r f, \tau} / \alpha_{\tau} \geq f_{r f, i(t)}^{P O} \sum_{\tau=1}^{t} C O_{r f, \tau} / \alpha_{\tau} \quad \forall r f, t \\
& -\sum_{\tau=1}^{t} f_{r f, i(t)}^{P O} \cdot C O_{r f, \tau} / \alpha_{\tau} \leq-f_{r f, i(t)}^{P O} \sum_{\tau=1}^{t} C O_{r f, \tau} / \alpha_{\tau} \quad \forall r f, t
\end{aligned}
$$

Similarly, for other tiers $i \neq i(t)$, we have:

$$
-\sum_{\tau=1}^{t} f_{r f, i}^{P O} \cdot C O_{r f, \tau} / \alpha_{\tau} \leq-f_{r f, i}^{P O} \sum_{\tau=1}^{t} C O_{r f, \tau} / \alpha_{\tau} \quad \forall r f, t, i \neq i(t)
$$

However,

$$
f_{r f, 1}^{P O} \sum_{\tau=1}^{t} C O_{r f, \tau} / \alpha_{\tau} \geq f_{r f, 2}^{P O} \sum_{\tau=1}^{t} C O_{r f, \tau} / \alpha_{\tau} \geq \ldots \ldots f_{r f, i(t)}^{P O} \sum_{\tau=1}^{t} C O_{r f, \tau} / \alpha_{\tau} \geq \ldots . . f_{r f, i^{\text {end }}}^{P O} \sum_{\tau=1}^{t} C O_{r f, \tau} / \alpha_{\tau}
$$

Therefore, for equation (A27) guaranteed to be valid for any tier $i$, we can use the last tier $i^{\text {end }}$ fraction instead which has minimum vale, that yields equation (A30):

$$
\sum_{\tau=1}^{t} f_{r f, i}^{P O} \cdot C O_{r f, \tau} / \alpha_{\tau} \geq f_{r f, i^{\text {end }}}^{P O} \sum_{\tau=1}^{t} C O_{r f, \tau} / \alpha_{\tau} \quad \forall r f, t, i
$$

Substituting (A14) and (A30) back in equation (A7) for any active tier $i$ in time $t$, we can obtain (A31) which is same as the desired expression (A1). 


$$
\begin{array}{r}
\sum_{\tau \leq t}\left(\text { Contsh }_{r f, \tau}^{\text {befretax }} / \alpha_{\tau}\right) \leq \sum_{i^{\prime}=1}^{i^{\prime} \leq i}\left(f_{r f, i^{\prime}}^{P O}-f_{r f, i^{\prime}-1}^{P O}\right) \cdot\left(x C_{r f, t}-L_{r f, i^{\prime}}\right)-f_{r f, i^{\text {end }}}^{P O} \cdot \sum_{\tau \leq t}\left(C O_{r f, \tau} / \alpha_{\tau}\right) \\
\forall r f, i, t
\end{array}
$$

Proposition 2: If the sliding scale variable for profit oil share of the contractor is daily oil production, the following inequalities are satisfied at the optimal solution of Model 3RF:

$$
\text { Contsh }_{r f, \tau}^{\text {beforetax }} /\left(\delta_{t} \alpha_{\tau}\right) \leq \sum_{i^{\prime}=1}^{i^{\prime} \leq i}\left(f_{r f, i^{\prime}}^{P O}-f_{r f, i^{\prime}-1}^{P O}\right) \cdot\left(x_{r f, t}^{\text {tot }}-L_{r f, i^{\prime}}\right)-f_{r f, i^{\text {end }}}^{P O} \cdot C O_{r f, \tau} /\left(\delta_{t} \alpha_{\tau}\right) \forall r f, i, t
$$

Proof: The proof follows similarly as for Proposition 1. However, in this case as the daily oil produced is the sliding scale variable, we do not apply the summation over time as we did for equation (A5). In addition, it is also assumed that the incremental tax is applicable only on the amount of oil production rate that is above the given tier threshold of the previous tier which is usually the case in practice. However, this type of tier structure is more popular for sliding scale royalties than profit oil described here.

\section{Appendix B}

\section{Sliding scale fiscal terms without binary variables:}

Proposition 3: Any sliding scale (either appearing in PSA, Concessionary system, etc.) where the sliding scale variable (e.g. cumulative oil, daily oil produced) and portion of oil that needs to split between oil company and government can be represented in terms of a fraction of the current revenues (production) or cumulative revenue (cumulative production), and the sliding scale is incremental, then we can represent the sliding scale fiscal terms without binary variables.

For example, in the following cases, we do not need any binary variable for representing the sliding scale fiscal terms:

(a) A concessionary/PSA system where the sliding scale is defined only for royalties based on the production. Eq. (B3(a))

(b) A concessionary/PSA system where the sliding scale is defined only for profit oil where royalty is a given fraction of the revenue and there is no cost oil. Eq. (B3(b))

(c) A concessionary/PSA system where the sliding scale is defined only for profit oil where royalty and cost oil are a given fraction of the revenues. Eq. (B3(c)) 


$$
\begin{aligned}
\vee & {\left[\begin{array}{c}
Z_{r f, i, t} \\
C o n S h_{r f, t}=f_{r f, i}^{e f f} \cdot R E V_{r f, t}^{\text {tot }} \\
L_{r f, i} \leq S V_{r f, t} \leq U_{r f, i}
\end{array}\right] } \\
S V_{r f, t}=x c_{r f, t} \text { or } x_{r f, t} & \forall r f, t
\end{aligned}
$$

Proof: The proof follows directly as in Proposition 1 where we use $f_{r f, i}^{\text {eff }}$ in place of $f_{r f, i}$. However, here we consider those cases (a)-(c) where the contractor's share can be represented directly as a fraction of revenue generated, the term that corresponds to the cost oil in RHS of equation (A5) will not appear as $f_{r f, i}^{e f f}$ has accounted for the cost oil and/or royalty if these are present. Therefore, we have (B4) instead, that reduces to the simpler version of equation (A1), i.e. (B5) in the case of cumulative oil produced as the sliding scale variable. Whereas, if the sliding scale variable is daily oil produced then corresponding eq. (A32) reduced to (B6) instead of eq. (B5)

ContSh $_{r f, t}^{\text {beforetax }} / \alpha_{t}=f_{r f, i(t)}^{\text {eff }} \cdot R E V_{r f, t}^{\text {tot }} / \alpha_{t}$, where tier $i(t)$ is active for rf in time t $\forall r f, t$ (B4)

$$
\sum_{\tau \leq t}\left(\text { Contsh }_{r f, \tau}^{\text {befortax }} / \alpha_{\tau}\right) \leq \sum_{i^{\prime}=1}^{i^{\prime} \leq i}\left(f_{r f, i^{\prime}}^{\text {eff }}-f_{r f f, i^{\prime}-1}^{\text {eff }}\right) \cdot\left(x c_{r f, t}-L_{r f, i^{\prime}}\right) \quad \forall r f, i, t
$$

Contsh $_{r f, \tau}^{\text {beforetax }} /\left(\delta_{t} \alpha_{\tau}\right) \leq \sum_{i^{\prime}=1}^{i^{\prime} \leq i}\left(f_{r f, i^{\prime}}^{\text {eff }}-f_{r f, i^{\prime}-1}^{\text {eff }}\right) \cdot\left(x_{r f, t}^{\text {tot }}-L_{r f, i^{\prime}}\right) \quad \forall r f, i, t$

In general, at-least one of the equation that corresponds to the active tier in (B5) or (B6) will be active in the optimal solution as contractor's share appears in the objective function. Therefore, the solution that it yields is usually the optimal for these cases, else it can serve as the valid inequality to generate the tight upper bound. This represents the sliding scale fiscal terms without binary variables.

\section{Appendix C}


Proposition 4: If the sliding scale variable for profit oil share of the contractor is cumulative oil produced, the following inequalities will provide a good approximation of the optimal solution of Model 3RF:

$$
\sum_{\tau \leq t}\left(\text { Contsh }_{r f, \tau}^{\text {beforetax }} / \alpha_{\tau}\right) \leq \sum_{i^{\prime}=1}^{i^{\prime} \leq i}\left(f_{r f, i^{\prime}}^{P O}-f_{r f, i^{\prime}-1}^{P O}\right) \cdot\left(x C_{r f, t}-L_{r f, i^{\prime}}\right)-f_{r f, 1}^{P O} \cdot \sum_{\tau \leq t}\left(C O_{r f, \tau} / \alpha_{\tau}\right) \forall r f, i, t \text { (C1) }
$$

Proof: Notice that in equation (A7), we use a relaxation of the second term in RHS as we do not know a priori when a tier $\mathrm{i}(\mathrm{t})$ becomes active and there is no limits that are available for cost oil for each tier which were available for cumulative oil produced. Ideally, it should be $f_{r f, 1}^{P O}$ for the years until first tier is active and then $f_{r f, 2}^{P O}$ for the duration of second tier and so on, to represent the second term accurately. Therefore, to obtain a better approximation of the second term, we can use the practical aspects of the problem. We know that most of the investments, cost oil recoveries take place in the initial years when low tier (1 or 2 ) are active, so it is better to use that fraction which approximate at-least the initial tiers as close the exact one as possible when costs are high. In the later years, cost oil values are small, so the approximation for the later years will not have significant impact on the solution quality. Therefore, fraction $f_{r f, 1}^{P O}$ is the best choice to use as an approximation in equation (A30) for the second term in equation (A7).

$$
\sum_{\tau=1}^{t} f_{r f, i}^{P O} \cdot C O_{r f, \tau} / \alpha_{\tau} \approx f_{r f, 1}^{P O} \sum_{\tau=1}^{t} C O_{r f, \tau} / \alpha_{\tau} \quad \forall r f, i, t
$$

On substituting (C2) in equation (A7) for any active tier i in current period t and using (A1), we can obtain equation (C1). 